\title{
ELASTICIDADES DE SUBSTITUIÇÃO DAS IMPORTAÇÕES NO BRASIL ${ }^{(*)}$
}

\author{
Honorio Kume ${ }^{a}$ \\ Guida Piani ${ }^{b}$
}

RESUMO: As estimativas dos impactos sobre as importações devido a acordos comerciais dependem fundamentalmente das elasticidades de substituição (ES) entre as importações de diferentes fornecedores estrangeiros. Este trabalho estima as ESs das importações do Brasil, para 42 setores da matriz de insumo produto de 2005, destacando as diferenças nos custos de transporte e na tarifa efetivamente paga entre os produtos, segundo os países de procedência. As elasticidades obtidas são estatisticamente significantes a $1 \%$ para 39 setores, com média simples de 6,6 e amplitude de 4,7 e 13,7. A disponibilidade das ES próprias para o Brasil permitirá obter cálculos mais precisos dos efeitos provocados por uma eventual participação brasileira em novos acordos de liberalização comercial.

PALAVRAS-CHAVE: Elasticidade de substituição; importações.

\section{CLASSIFICAÇÃO JEL: F13.}

Artigo recebido em 28/08/2013 e aprovado em 28/12/2013. Este trabalho foi elaborado quando os autores estavam lotados na Diretoria de Estudos e Relações Econômicas e Políticas Internacionais do Instituto de Pesquisa Econômica e Aplicada (DINTE-IPEA).

a Doutor em Economia e professor associado da Faculdade de Ciências Econômicas da Universidade do Estado do Rio de Janeiro (FCE-UERJ). Contato: honorio.kume@gmail.com.

b Mestre em Economia pela Pontifícia Universidade Católica do Rio de Janeiro (PUC-Rio). Contato: guidapiani1@gmail.com. 


\section{ELASTICITIES OF IMPORT SUBSTITUTION IN BRAZIL}

ABSTRACT: Estimates of the impacts on imports due to trade agreements depend fundamentally on the elasticity of substitution between imports from different foreign suppliers. This paper estimate the elasticity of substitution for Brazilian imports, for 42 sectors of input-output table for 2005, highlighting the differences in transportation costs and the effectively paid tariffs between products, depending on the country of origin. The elasticities obtained are statistically significant for $1 \%$ to 39 sectors, with the arithmetic average of 6.6 and the amplitude of 4.7 and 13.7. The availability of the own elasticities for Brazil will provide more accurate calculations of the effects of a possible Brazilian participation in new trade liberalization agreements.

KEYWORDS: Elasticity of substitution; imports. 


\section{INTRODUÇÃO}

A participação do Brasil nas negociações comerciais, seja de natureza multilateral, como na Rodada Doha, seja de caráter regional, como nas discussões para a formação de uma área de livre comércio entre o Mercado Comum do Sul (Mercosul) e a União Europeia (UE), tem estimulado a elaboração de estudos visando calcular os impactos sobre as exportações e as importações brasileiras diante destes cenários de liberalização comercial.

Tanto nos modelos de equilíbrio geral computável como nos de equilíbrio parcial, as estimativas dos impactos comerciais dependem fundamentalmente das elasticidades de substituição (ES) entre produtos domésticos e importados e entre as importações de diferentes fornecedores estrangeiros. No entanto, diante da falta de estimativas destas elasticidades específicas para o Brasil, os trabalhos realizados recorrem aos valores escolhidos arbitrariamente.

Carvalho e Parente (2000) com base em um modelo de equilíbrio parcial, avaliam o impacto da Área de Livre Comércio das Américas (ALCA) sobre o comércio brasileiro aplicando uma ES de 1,5 obtida de Laird e Yeats (1986). Este valor é bastante utilizado, pois consta como a elasticidade básica no software for Market Analysis and Restrictions on Trade (Smart) (UNCTAD e WORLD BANK, 1989), desenvolvido para auxiliar os países em desenvolvimento a simular os impactos de comércio provocados pelas reduções tarifárias nas negociações multilaterais da Rodada Uruguai. Os autores argumentam que este valor foi retirado de Cline et al. (1978) que, surpreendentemente, utilizam a elasticidade de 2,5 em vez de 1,5 para calcular os impactos comerciais da Rodada Tóquio. Além disso, Cline et al. (1978) não estimaram esta elasticidade, mas escolheram este valor baseado em estudos anteriores.

As estimativas que utilizam modelos de equilíbrio geral computável geralmente aplicam uma ES mais elevada, mas comum para todos os setores. Harrison et al. (2003) utilizam a elasticidade de 30 para simular os impactos dos acordos comerciais, entre o Mercosul e a UE e no âmbito da ALCA, sobre a distribuição de renda e o nível de pobreza no Brasil. Gurgel (2006) utiliza a elasticidade de 8 para simular os efeitos das reduções tarifárias na Rodada Doha sobre o agronegócio brasileiro. Azevedo (2008) avalia o impacto do Mercosul sobre o bem-estar dos países-membros e não membros com base no modelo de equilíbrio geral do Global Trade Analysis Project (Gtap) que dispõe de elasticidades para 40 setores, entre 3,6 e 10,4, mas com pequena variabilidade, atribuindo 4,4 para 16 setores e 5,6 também para 16 setores (Gtap, versão 5, citado por Hertel et al., 2007, p. 622).

Batista (2001), ao contrário dos citados anteriormente, analisa o impacto de um acordo de livre comércio entre o Brasil e a UE estimando a elasticidade de substituição entre as importações da UE e dos demais países para 18 produtos - segundo a classifi- 
cação a 8 dígitos da Nomenclatura Comum do Mercosul (NCM). A estimativa baseou-se em uma regressão simples entre a variação mensal anualizada da quantidade relativa das importações provenientes da UE e dos demais países e do preço relativo no período de 1998-2000. Os resultados mostram uma elasticidade baixa, de aproximadamente igual a um para 14 produtos, exceto para partes de caldeiras (elasticidade igual a 2), partes de aparelhos para radiotelefonia $(1,7)$, outros veículos $(3,2)$ e outros aviões $(1,7)$.

Posteriormente, Tourinho, Kume e Pedroso (2007) utilizaram séries trimestrais de índices agregados de quantum e de preços da produção doméstica e das importações de 28 setores $^{1}$ no período 1986-2002 e obtiveram ES estatisticamente significantes ${ }^{2}$ para 24 setores, variando entre 0,2 e 3,6. Os resultados foram utilizados em diversos estudos. Por exemplo, em modelos de equilíbrio geral, por Cury, Coelho e Corseuil (2005) para analisar os efeitos distributivos da abertura comercial brasileira nos anos 1990 e, de equilíbrio parcial, por Kume e Piani (2005) para avaliar o impacto no comércio bilateral Brasil e Estados Unidos decorrente da ALCA.

Recentemente, Barroso (2010), seguindo a metodologia proposta por Feenstra (1994), estimou a ES entre as importações de diversas origens por produto (6 dígitos da NCM) no período 1989-2008. Para evitar o viés de simultaneidade, a estimativa foi realizada por meio de uma equação na forma reduzida entre a participação das importações de diversas fontes e os respectivos preços unitários. Em seguida, as elasticidades obtidas são agregadas para 18 setores e variam entre 3 e 13,8. Entretanto, provavelmente devido à disponibilidade de dados, ignora as reduções tarifárias ocorridas na abertura comercial brasileira na primeira metade da década de 1990.

As ES de Barroso (2010) são bastante superiores às obtidas por Tourinho, Kume e Pedroso (2007). Isto se deve ao fato de os produtos com elasticidades menores apresentarem grandes variações nos preços, influenciando negativamente as estimativas baseadas em dados agregados (Imbs e Mejean, 2009).

O objetivo deste trabalho é estimar as ES das importações entre diversos fornecedores externos, por setor da matriz de insumo produto do Brasil de 2003 (IBGE, 2005). Este estudo segue a metodologia proposta por Hertel et al. (2007), que enfatiza as diferenças nos custos de importação de cada produto, por país de origem, devido à tarifa efetivamente paga e ao custo de transporte (despesas de frete e seguro) em um determinado ano (cross-section). Desta forma, evita o viés negativo nas ES estimadas com séries temporais.

Este trabalho se diferencia de Barroso (2010) por incorporar na estimativa das ES a tarifa efetivamente paga, que varia segundo o grau de preferência tarifária concedido

1 Refere-se à classificação por setor, nível 50, da matriz de insumo produto do Brasil: 1990-1996.

2 Sendo significativas no nível de 5\% para 20 setores, ao nível de $10 \%$ para dois setores e no nível de $20 \%$ para dois setores. 
pelo Brasil ao país exportador e pela redução obtida pelo comprador ao se enquadrar em regimes especiais de tributação vigentes, tais como drawback e Zona Franca de Manaus. Assim, para um importador, os produtos se diferenciam segundo o país exportador, pelo custo de transporte e pela tarifa paga. Apesar disto, devido às diferenças nos métodos de estimação, não se pode afirmar que as estimativas obtidas neste estudo sejam mais confiáveis do que as de Barroso (2010). No entanto, ao disponibilizar um novo conjunto de ES por setor, espera-se que contribua para tornar mais robusta as estimativas dos impactos econômicos decorrentes da liberalização de importações.

Além desta breve introdução, o trabalho está dividido em quatro itens. No item 2, serão descritos os procedimentos, as fontes de dados e a estatística descritiva destas informações. No item 3, serão apresentadas as estimativas da ES e destacada a sua relevância econômica aplicando-se estas elasticidades no cálculo do desvio de comércio nas importações brasileiras em um eventual acordo de livre comércio com a UE e comparando-o com os resultados obtidos com outras elasticidades. No item 4 , serão resumidas as principais conclusões.

\section{PROCEDIMENTOS METODOLÓGICOS, FONTE DOS DADOS E ESTATÍSTICA DESCRITIVA}

\subsection{METODOLOGIA}

A utilidade de um bem composto formado pelo bem doméstico e por um agregado de produtos importados é dada por:

$$
U_{i}=\left[D_{i}^{\frac{\varphi_{i}-1}{\varphi_{i}}}+M_{i}^{\frac{\varphi_{i}-1}{\varphi_{i}}}\right]^{\frac{\varphi_{i}}{\varphi_{i}-1}}
$$

Onde:

$U_{i}=$ utilidade do bem composto $i$;

$D_{i}=$ bem doméstico $i$;

$M_{i}=$ bem importado agregado $i$; e

$\varphi_{i}=$ ES entre os bens doméstico e importado.

O bem importado agregado é dado por:

\footnotetext{
Versão modificada da metodologia adotada por Hertel et al. (2007).
} 


$$
M_{i}=\left[\sum_{r=1}^{R} M_{i r}^{\frac{\sigma_{i}-1}{\sigma_{i}}}\right]^{\frac{\sigma_{i}}{\sigma_{i}-1}}
$$

Onde:

$M_{i r}=$ bem importado i proveniente do país $r$; e

$\sigma_{i}=$ ES entre os bens importados de diversos países.

Inicialmente, o país importador maximiza a função utilidade - equação (1) - do bem $i$, sujeita ao gasto total determinado exogenamente, e obtém a quantidade $M_{i}$. Multiplicando-se esta quantidade pelo preço de importação, tem-se o valor global das importações do bem $i$ :

$$
V M_{i}=\frac{G_{i}}{P_{m i}^{\varphi_{i}} P_{i}^{\varphi_{i}-1}}
$$

\section{Onde:}

$V M_{i}=$ valor ótimo das importações do bem $i$;

$G_{i}=$ gasto total sobre o bem $i$;

$P_{m i}=\left[\sum_{r=1}^{R} P_{m i r}^{1-\sigma_{i}}\right]^{\frac{1}{1-\sigma_{i}}}=$ índice de preço do bem i importado agregado;

$P_{i}=\left[P_{d i}^{1-\varphi_{i}}+P_{m i}^{1-\varphi_{i}}\right]^{\frac{1}{1-\sigma_{i}}}=$ índice de preço do bem composto $i$; e

$P_{d i}=$ preço do bem doméstico $i$.

Uma vez determinado o valor das importações do bem $i\left(V M_{i}\right)$ e dado o preço de cada país exportador, a quantidade importada de cada país fornecedor é obtida maximizando-se a equação (2):

$$
Q_{m i r}=\left[\frac{P_{m i r}}{P_{m i}}\right]^{1-\sigma_{i}} V_{m i} P_{m i r}^{-1}
$$

Onde:

$Q_{\text {mir }}=$ quantidade importada do bem $i$ proveniente do país $r$; e $P_{\text {mir }}=$ preço do bem $i$ importado do país $r$.

O preço internado do bem $i$ importado depende do preço Free on Board (FOB) em cada país exportador, acrescido do custo de transporte e da tarifa efetivamente paga: 


$$
P_{\text {mir }}=P_{\text {fobir }}\left(1+C T_{i r}+T_{i r}+C T_{i r}^{*} T_{i r}\right)
$$

Onde:

$P_{\text {mir }}=$ preço do bem importado i disponibilizado no país;

$P_{\text {fobir }}=$ preço FOB do bem i no país exportador $r$;

$C T_{i r}=$ alíquota do custo de transporte de transporte do bem i proveniente do país $r$; $T_{i r}=$ alíquota da tarifa efetivamente paga do bem $i$ originária do país $r$.

O termo $C T_{\text {ir }}{ }^{*} T_{\text {ir }}$ deve-se à base de cálculo da tarifa aduaneira no Brasil que é o preço inclusive o custo de transporte.

Substituindo a equação (5) na equação (4) e multiplicando por $P_{\text {mir }}$, tem-se:

$$
V M_{i r}=V M_{i}\left[\frac{P_{F O B i}\left(1+C T_{i r}+T_{i r}+C T_{i r} * T_{i r}\right)}{P_{m i}}\right]^{1-\sigma_{i}}
$$

Aplicando o logaritmo natural na equação (6), obtém-se:

$$
L n V M_{i r}=\operatorname{LnVM_{i}}+\left(1-\sigma_{i}\right) \operatorname{Ln} P_{f o b i}+\left(1-\sigma_{i}\right) \operatorname{Ln}\left(1+C T_{i r}+T_{i r}+C T_{i r} * T_{i r}\right)-\left(1-\sigma_{i}\right) \operatorname{Ln} P_{m i}(7)
$$

A equação (7) é estimada da seguinte forma:

$$
\operatorname{LnVM} M_{i r}=a_{0}+a_{i r}+a_{1} \operatorname{Ln}\left(1+C T_{i r}+T_{i r}+C T_{i r} * T_{i r}\right)+e_{i r}
$$

A constante $\left(a_{0}\right)$ captura as variáveis $V M_{i}$ e $P m_{i}$ e o efeito fixo - país exportador para cada bem i $\left(a_{i r}\right)$ representa as características da oferta, tais como o preço FOB e a qualidade do produto. Assim, todos os exportadores são comparáveis, à exceção do custo de transporte e da tarifa efetivamente paga pelo importador.

O parâmetro $a_{1}=\left(1-\sigma_{i}\right)$ mede a variação nas importações proveniente de cada país exportador em decorrência de uma mudança nos custos de comércio.

\subsection{FONTE DOS DADOS E ESTATÍSTICA DESCRITIVA}

As importações do Brasil em valor FOB e Cost, Insurance and Freight (CIF) em dólares e a receita arrecadada do Imposto de Importação (II) e o valor tributável das importações, ambos em reais, por produto (8 dígitos da NCM) e por país de procedência, 
foram obtidos da Secretaria da Receita Federal (SRF) do Ministério da Fazenda (MF) para 2003 e 2006. Os anos referem-se à disponibilidade de dados.

A tarifa efetivamente paga por produto foi calculada dividindo-se a receita do II pelo valor tributável das importações ${ }^{4}$.

A alíquota do custo de transporte foi obtida dividindo-se a diferença entre os valores CIF e FOB das importações sobre o valor FOB das importações.

Os produtos foram distribuídos por setor da matriz de insumo produto do IBGE (2005) e por setor do Gtap.

A Tabela 1 apresenta um conjunto de medidas estatísticas da tarifa paga, da alíquota do custo de transporte e do valor das importações. A tarifa média simples atinge $10,2 \%$, enquanto a média ponderada pelas importações é de apenas 4,4\%, indicando uma concentração das importações em produtos com tarifas menores. A tarifa máxima de $55 \%{ }^{5}$ é compatível com a alíquota máxima estabelecida pelo Brasil na Lista Nacional de Exceção à Tarifa Externa Comum (TEC) do Mercosul.

Tabela 1 - Estatística descritiva: tarifa paga, alíquota do custo de transporte e importações FOB

\begin{tabular}{l|c|c|c|c|c}
\hline \multicolumn{1}{c|}{ Estatística } & $\begin{array}{c}\text { Tarifa } \\
\mathbf{( \% )}\end{array}$ & $\begin{array}{c}\text { Custo de } \\
\text { transporte } \\
\mathbf{( \% )}\end{array}$ & $\begin{array}{c}\text { Custo de } \\
\text { transporte } \\
\mathbf{( \% )}(\mathbf{1})\end{array}$ & $\begin{array}{c}\text { Importações } \\
\mathbf{( U S \$ \mathbf { 1 . 0 0 0 } )}\end{array}$ & $\begin{array}{c}\text { Importações } \\
\text { (US\$ 1.000) } \\
\mathbf{( 2 )}\end{array}$ \\
\hline Média simples & 10,2 & 47,5 & 12,3 & 834 & 353 \\
\hline Média ponderada & 4,4 & 5,1 & 5,1 & - & - \\
\hline Mediana & 12,0 & 5,8 & 5,8 & 20 & 20 \\
\hline Mínimo & 0 & 0 & 0,2 & 0,000001 & 0,01 \\
\hline Máximo & 55 & 912.011 & 205 & 3.832 .305 & 12.020 \\
\hline Desvio-padrão & 7,2 & 37,9 & 20,9 & 14.765 & 1.109 \\
\hline Número de observações & 167.099 & 167.099 & 163.758 & 167.099 & 163.757 \\
\hline
\end{tabular}

Notas: (1) Exclui 2\% das observações com menores e maiores alíquotas. (2) Exclui $2 \%$ das observações com menores e maiores valores.

Fonte: Elaboração própria com base em dados da Secretaria da Receita Federal do Ministério da Fazenda (SRF/MF).

A média simples da alíquota do custo de transporte de $47,5 \%$ é excessivamente elevada ${ }^{6}$, provavelmente em virtude de erros de medida em alguns produtos. Por exemplo, o custo de transporte máximo de 912,011\% não deve ser compatível em transações comerciais usuais. Além disso, um custo de transporte nulo também é surpre-

4 O II incide sobre o valor tributável que corresponde ao valor CIF das importações, que eventualmente pode ser alterado quando a SRF/MF considera que o preço declarado pelo importador não corresponde ao verdadeiro preço da transação.

5 Esta alíquota é atribuída às importações de pêssego em calda.

6 Hummels (2001) calcula um frete médio de 23,1\% para o Brasil no período 1991-1994. 
endente, exceto se o exportador adiciona esta despesa no preço do produto, mas equivocadamente informa como preço FOB.

Para atenuar a presença de produtos com custos de transporte excessivamente altos ou baixos (outliers), os produtos foram ordenados segundo as alíquotas do custo de transporte, eliminando-se 167 produtos com as maiores alíquotas e 167 produtos com as menores alíquotas, o que corresponde no total a $2 \%$ do total de produtos. A média simples diminui para $12,3 \%$ e a média ponderada pelas importações permanece constante. Isso significa que os produtos com alíquotas atípicas de custo de transporte apresentam reduzidos valores de importação. A alíquota máxima passa a ser $205 \%$.

As importações também apresentam uma grande variabilidade, com média simples de US\$ 834 mil, mediana de US\$ 20 mil e variando de um valor próximo a zero a US\$ 3,8 bilhões. Novamente, os produtos foram ordenados segundo o valor das importações e eliminaram-se 167 produtos com maiores valores e 167 com valores menores, equivalentes a $2 \%$ das observações totais. Com este procedimento, o valor das importações passa a ter uma média de US\$ 353 mil e uma amplitude entre US\$ 10 e US\$ 12 milhões.

Para ilustrar as diferenças das tarifas pagas e das alíquotas dos custos de transporte, por país de origem das importações, a Tabela 2 apresenta as estatísticas descritivas, excluindo-se $2 \%$ das observações que apresentam alíquotas do custo de transporte atípicas, para quatro países escolhidos que apresentam distâncias diferentes, medidas entre os centros econômicos do Brasil e os respectivos países (Kume e Piani, 2000).

\section{Tabela 2 - Tarifa paga (\%) e alíquota do custo de transporte (\%) (1), países escolhidos pela distância}

\begin{tabular}{|c|c|c|c|c|c|c|c|c|}
\hline País & \multicolumn{2}{|c|}{ Argentina } & \multicolumn{2}{|c|}{ Alemanha } & \multicolumn{2}{|c|}{ Estados Unidos } & \multicolumn{2}{|c|}{ Japão } \\
\hline Distância do Brasil (km) & \multicolumn{2}{|c|}{1.006} & \multicolumn{2}{|c|}{5.855} & \multicolumn{2}{|c|}{6.239} & \multicolumn{2}{|c|}{11.336} \\
\hline Estatística & Tarifa & Frete & Tarifa & Frete & Tarifa & Frete & Tarifa & Frete \\
\hline Média simples & 1,5 & 7,2 & 9,8 & 9,5 & 9,3 & 11,0 & 9,1 & 11,4 \\
\hline Média ponderada & 0,1 & 5,5 & 7,8 & 3,9 & 5,2 & 4,5 & 6,2 & 5,1 \\
\hline Mediana & 0,0 & 3,6 & 11,4 & 4,6 & 10,0 & 5,9 & 10,0 & 5,4 \\
\hline Mínimo & 0,0 & 0,2 & 0,0 & 0,2 & 0,0 & 0,2 & 0,0 & 0,2 \\
\hline Máximo & 24 & 192 & 42 & 205 & 36 & 200 & 36 & 203 \\
\hline Desvio-padrão & 4,1 & 14 & 6,6 & 17,4 & 6,6 & 905 & 6,9 & 242 \\
\hline Número de observações & \multicolumn{2}{|c|}{5.569} & \multicolumn{2}{|c|}{10.401} & \multicolumn{2}{|c|}{12.462} & \multicolumn{2}{|c|}{6.802} \\
\hline
\end{tabular}

Nota: (1) Exclui 2\% das observações com alíquotas menores e maiores.

Fonte: Elaboração própria com base em dados de SRF/MF.

Novamente, tanto a tarifa como o custo de transporte ponderado pelas importações são inferiores à média simples, mostrando que os importadores procuram evitar os bens com custos de comércio mais elevados. A tarifa paga nas importações prove- 
nientes da Argentina é bastante inferior à dos demais países devido à isenção concedida no âmbito do Mercosul.

Como esperado, nota-se que o custo de transporte não cresce linearmente com a distância entre o Brasil e o país exportador. A Alemanha é quase seis vezes mais distante do que a Argentina, mas o custo de transporte aumenta apenas de 7,2\% para $9,5 \%$, quando medido pela média simples, e de $3,6 \%$ para $4,6 \%$, pela mediana. O Japão localiza-se a uma distância de cerca de duas vezes maior do que a dos Estados Unidos. No entanto, a alíquota média simples do custo de transporte aumenta apenas 0,4 pontos de percentagem e a mediana cai 0,5 pontos de percentagem.

Como o custo de transporte depende do peso e do volume da mercadoria, as alíquotas agregadas por país de procedência são influenciadas pela composição das importações. Para contornar este problema, foi calculada a alíquota média do custo de transporte de automóveis, ponderada pelas importações: 1,3\% da Argentina, 2,3\% da Alemanha, 2,5\% dos Estados Unidos e 5,9\% do Japão. Neste caso, uma relação mais próxima entre a distância e o custo de transporte é válida, exceto entre a Argentina e a Alemanha.

\section{RESULTADOS}

A Tabela 3 apresenta as estimativas das elasticidades de substituição $\left(\sigma_{i}=1-a_{1}\right)$ das importações baseadas na equação (8), para 39 setores comercializáveis da matriz de insumo produto de 2005. Em todos os procedimentos de estimação, não foi possível obter elasticidades estatisticamente diferentes de zero ou não puderam ser estimadas, por apresentarem um número de observações insuficiente, em três setores: petróleo e gás natural (código 201), minério de ferro (202) e álcool (310). No primeiro, as importações são feitas pela Petrobras e nos demais predomina a atividade exportadora. Assim, a análise a seguir exclui estes setores. No Apêndice A são mostradas as equações estimadas.

$\mathrm{Na}$ coluna (a) foram utilizadas todas as observações disponíveis. As elasticidades são significantes a $1 \%$, à exceção dos três setores citados anteriormente, com média simples de 5,3 e amplitude entre 3 e 10.

$\mathrm{Na}$ coluna (b) foram excluídas as observações com alíquotas de custos de transporte atípicas, definidos como $1 \%$ do número de produtos com as maiores alíquotas e $1 \%$ com as menores. Também foram eliminados $2 \%$ dos produtos que apresentaram valores de importação excessivamente elevados (1\%) ou reduzidos (1\%). A exclusão destas observações aumenta as elasticidades, a média simples atinge 6,5 e a amplitude entre 3,3 e 12,7. A elasticidade de caminhões e ônibus deixa de ser estatisticamente significante. 
Como dito anteriormente, os produtos com custos de transporte atípicos decorrem provavelmente de erros de medida, portanto, não dependem do setor em que são classificados. Os valores de importação não apresentam erros de medida, mas seus valores extremos podem influenciar as estimativas das ES. Logo, como as estimativas são realizadas por setor, o procedimento mais apropriado é verificar os valores atípicos das importações em cada setor. Na coluna 3, este método é adotado, mas as elasticidades não se alteram de forma importante. A única mudança ocorre em caminhões e ônibus cuja elasticidade torna-se novamente estatisticamente significante.

A coluna (d) mostra as ES estimadas por Barroso (2010) para efeitos de comparação com os resultados obtidos neste trabalho. Porém, este autor lista as elasticidades obtidas na classificação setorial da matriz de insumo produto de 1990-1996 com o objetivo de mostrar que, devido à metodologia adotada, seus resultados são superiores aos de Tourinho, Kume e Pedroso (2007). Assim, somente foi possível obter resultados comparáveis para 23 setores. De maneira geral, observa-se que as estimativas de Barroso (2010) são substancialmente maiores.

\section{Tabela 3 - Estimativa da elasticidade de substituição, por setor da matriz de insumo} produto de 2005

\begin{tabular}{|c|c|c|c|c|c|}
\hline Código & Setor & $\begin{array}{c}\text { Todas as } \\
\text { observações } \\
\text { (a) }\end{array}$ & $\begin{array}{c}\text { Exclui } \\
\text { observações } \\
\text { atípicas } \\
\text { (b) }\end{array}$ & $\begin{array}{c}\text { Exclui } \\
\text { observações } \\
\text { atípicas, por } \\
\text { setor } \\
\text { (c) }\end{array}$ & $\begin{array}{c}\text { Barroso } \\
\text { (d) }\end{array}$ \\
\hline 101 & Agricultura, silvicultura, exploração florestal & $5,7^{* * *}$ & $5,8^{* * *}$ & 6,0 & 10,9 \\
\hline 102 & Pecuária e pesca & $3,0^{* * *}$ & $5,5^{* * *}$ & 5,0 & \\
\hline 201 & Petróleo e gás natural & 0,2 (ns) & ne & 0,2 (ns) & \\
\hline 202 & Minério de ferro & 2,9 (ns) & ne & ne & \\
\hline 203 & Outros produtos extrativos & $4,1^{* * *}$ & $4,5^{\star * *}$ & $4,8^{\star * *}$ & \\
\hline 301 & Alimentos e bebidas & $4,1^{* * *}$ & $6,2^{* * *}$ & $6,0^{* * *}$ & 8,7 \\
\hline 302 & Produtos do fumo & $5,4^{* * *}$ & $6,8^{* * *}$ & $6,6^{* * *}$ & 9,6 \\
\hline 303 & Têxteis & $4,6^{* * *}$ & $7,1^{* * *}$ & $7,0^{* * *}$ & 10,1 \\
\hline 304 & Artigos do vestuário e acessórios & $4,8^{* * *}$ & $5,7^{* * *}$ & $5,6^{\star * *}$ & 8,5 \\
\hline 305 & Artefatos de couro e calçados & $5,0^{* * *}$ & $6,0^{* * *}$ & $6,0^{* * *}$ & 7,0 \\
\hline 306 & Produtos de madeira & $4,0^{* * *}$ & $5,0^{* * *}$ & $5,0^{* * *}$ & 6,7 \\
\hline 307 & Celulose e produtos de papel & $4,2^{* * *}$ & $6,4^{* * *}$ & $6,3^{* * *}$ & 10,1 \\
\hline 308 & Jornais, revistas, discos & $3,6^{* * *}$ & $5,1^{* * *}$ & $5,0^{* * *}$ & \\
\hline 309 & Refino de petróleo e coque & $6,5^{* * *}$ & $6,3^{* * *}$ & $7,4^{* * *}$ & 3,2 \\
\hline 310 & Álcool & 3,3 (ns) & $3,3(\mathrm{~ns})$ & $6,9(\mathrm{~ns})$ & \\
\hline 311 & Produtos químicos & $4,9^{* * *}$ & $7,2^{\star * *}$ & $7,1^{\star * *}$ & 6,1 \\
\hline
\end{tabular}




\begin{tabular}{|c|c|c|c|c|c|}
\hline 312 & Fabricação de resina e elastômeros & $5,3^{* * *}$ & $7,2^{* * *}$ & $7,1^{* * *}$ & \\
\hline 313 & Produtos farmacêuticos & $7,8^{\star * *}$ & $8,6^{* * *}$ & $8,6^{* * *}$ & 5,0 \\
\hline 314 & Defensivos agrícolas & $10,0^{* * *}$ & $12,2^{* * *}$ & $13,7^{* * *}$ & \\
\hline 315 & Perfumaria, higiene e limpeza & $4,5^{\star * *}$ & $5,5^{* * *}$ & $5,4^{* * *}$ & \\
\hline 316 & Tintas, vernizes, esmaltes e lacas & $4,4^{* * *}$ & $6,3^{* * *}$ & $6,3^{* * *}$ & \\
\hline 317 & Produtos e preparados químicos diversos & $5,2^{* * *}$ & $6,9^{* * *}$ & $6,7^{* * *}$ & \\
\hline 318 & Artigos de borracha e plástico & $4,8^{\star * *}$ & $5,9^{* * *}$ & $5,9^{* * *}$ & 5,9 \\
\hline 319 & Cimento & $3,8^{* * *}$ & $6,0^{* * *}$ & $6,1^{\star * *}$ & 3,0 \\
\hline 320 & Outros produtos de minerais não metálicos & $4,5^{* * *}$ & $5,5^{* * *}$ & $5,4^{* * *}$ & 3,0 \\
\hline 321 & Fabricação de aço e derivados & $5,0^{* * *}$ & $6,7^{* * *}$ & $6,5^{* * *}$ & 6,7 \\
\hline 322 & Metalurgia de metais não ferrosos & $5,9^{* * *}$ & $7,9^{* * *}$ & $8,0^{* * *}$ & 4,5 \\
\hline 323 & Produtos de metal & $4,9^{* * *}$ & $6,4^{* * *}$ & $6,4^{* * *}$ & 6,7 \\
\hline 324 & Máquinas e equipamentos & $6,1^{* * *}$ & $8,1^{* * *}$ & $8,0^{* * *}$ & 4,2 \\
\hline 325 & Eletrodomésticos & $5,2^{* * *}$ & $5,7^{* * *}$ & $5,6^{* * *}$ & \\
\hline 326 & Máquinas de escritório e equips. de informática & $6,0^{* * *}$ & $6,3^{* * *}$ & $6,2^{* * *}$ & \\
\hline 327 & Máquinas, aparelhos e materiais elétricos & $6,3^{* * *}$ & $7,2^{\star * *}$ & $7,2^{\star * *}$ & 3,9 \\
\hline 328 & Material eletrônico e equips. de comunicação & $5,3^{* * *}$ & $6,4^{\star * *}$ & $6,7^{* * *}$ & \\
\hline 329 & Aparelhos/instrumentos médico e ótico & $7,2^{* * *}$ & $8,1^{* * *}$ & $7,9^{* * *}$ & \\
\hline 330 & Automóveis, camionetas e utilitários & $8,3^{* * *}$ & $6,3^{* * *}$ & $7,2^{* * *}$ & 4,1 \\
\hline 331 & Caminhões e ônibus & $7,4^{* * *}$ & 3,3 (ns) & $6,0^{* * *}$ & 4,1 \\
\hline 332 & Peças e acessórios para veículos & $5,8^{* * *}$ & $6,8^{* * *}$ & $6,9^{* * *}$ & 4,7 \\
\hline 333 & Outros equipamentos de transporte & $5,5^{* * *}$ & $8,4^{* * *}$ & $8,9^{* * *}$ & 4,7 \\
\hline \multirow[t]{6}{*}{334} & Móveis e produtos diversos & $3,2^{\star * *}$ & $4,7^{\star * *}$ & $4,7^{\star * *}$ & \\
\hline & Média (1) & 5,3 & 6,5 & 6,6 & \\
\hline & Mediana (1) & 5,1 & 6,3 & 6,4 & \\
\hline & Máxima (1) & 10,0 & 12,7 & 13,7 & \\
\hline & Mínima & 3,0 & 3,3 & 4,7 & \\
\hline & Desvio-padrão(1) & 1,4 & 1,5 & 1,6 & \\
\hline
\end{tabular}

Notas: $\left.{ }^{* \star}\right)$ significante no nível de $5 \% ;{ }^{* * *}$ significante ao nível de $1 \%$; ns = não significante; ne = não estimado devido a observações insuficientes. (1) Exclui os setores de petróleo e gás natural, minério de ferro e álcool.

Fonte: Colunas (a), (b) e (c), elaboração própria. Coluna (d) elaborada com base em Barroso (2010, p. 47).

Considerando a coluna (c), os cinco setores com maiores elasticidades são: Defensivos agrícolas (13,7); Outros equipamentos de transporte (8,9); Produtos farmacêuti$\cos (8,6)$; Máquinas e equipamentos (8); e Metalurgia de metais não ferrosos (8). Os setores com menores elasticidades são: Móveis e produtos diversos (4,7); Outros produtos extrativos (4,8); Produtos de madeira (5); Jornais, revistas, discos (5); e Pecuária e pesca (5). 


\subsection{POR QUE HÁ DIFERENÇAS SETORIAIS NAS ES?}

A princípio, quanto maior for a percepção dos compradores sobre a diferenciação dos produtos de um setor, maior será a ES. No entanto, além das características físicas do bem, a diferenciação pode estar associada a outros fatores, tais como a disponibilidade no tempo, a conveniência na compra, os serviços oferecidos após a aquisição e as qualidades não observáveis do produto. Os compradores também podem considerar outros custos de transação como eventuais interrupções na oferta, atrasos na entrega etc. (Bloningen e Wilson, 1999).

Assim, sem conhecer as especificidades dos produtos de um setor, não é fácil prever a ES. Em móveis e produtos diversos e outros produtos extrativos, seria esperada uma baixa elasticidade por serem grupos de produtos heterogêneos, o que é confirmada pelas elasticidades obtidas.

A Tabela 4 mostra a distribuição de frequência dos setores por faixas de elasticidades mostradas na Tabela 3. Nota-se na coluna (a) uma concentração nas faixas entre 4 e 4,9 (12 setores) e 5 e 5,9 (11 setores). Após a exclusão dos valores extremos de custos de transporte e de valor de importação, a elasticidade modal encontra-se entre 6 e 6,9 (14 setores).

Tabela 4 - Distribuição de frequência dos setores por classes de ES

\begin{tabular}{c|c|c|c}
\hline Classe & $\begin{array}{c}\text { Todas as } \\
\text { observações } \\
(\mathbf{a})\end{array}$ & $\begin{array}{c}\text { Exclui observações } \\
\text { atípicas } \\
(\mathbf{b})\end{array}$ & $\begin{array}{c}\text { Exclui observações } \\
\text { atípicas por setor } \\
\text { (c) }\end{array}$ \\
\hline $3 \leq \mathrm{ES}<4$ & 4 & 2 & 2 \\
\hline $4 \leq \mathrm{ES}<5$ & 12 & 9 & 8 \\
\hline $5 \leq \mathrm{ES}<6$ & 11 & 14 & 14 \\
\hline $6 \leq \mathrm{ES}<7$ & 4 & 5 & 7 \\
\hline $7 \leq \mathrm{ES}<8$ & 3 & 5 & 5 \\
\hline $\mathrm{ES} \geq 8$ & 2 & 35 & 36 \\
\hline Total & 36 & & \\
\hline
\end{tabular}

Fonte: Elaboração própria com base em dados da Tabela 3.

A Tabela 5 apresenta as estimativas da ES para 40 setores do Gtap ao lado daquelas obtidas por Hertel et al. (2007) - que utilizam a mesma metodologia nas importações de Argentina, Chile, Estados Unidos, Nova Zelândia, Paraguai e Uruguai, com produtos a cinco dígitos da Classificação Uniforme de Comércio Internacional (CUCI), em 1992 - e as adotadas como padrão no modelo de equilíbrio geral computável do Gtap (versão 5). No apêndice B são apresentadas as equações estimadas nesta classificação. 
Tabela 5 - Estimativas da elasticidade de substituição: Gtap versão 5, Hertel et al. e próprias

\begin{tabular}{|c|c|c|c|c|}
\hline Código & Setor Gtap & $\begin{array}{l}\text { GTAP V5 } \\
\text { (a) }\end{array}$ & $\begin{array}{l}\text { Hertel et al. } \\
\text { (b) }\end{array}$ & $\begin{array}{c}\text { Estimativa } \\
\text { (c) }\end{array}$ \\
\hline 1 & Arroz & 4,4 & $10,1^{* *}$ & $11,2^{*}$ \\
\hline 2 & Trigo & 4,4 & $8,9^{* *}$ & $57,2(\mathrm{~ns})$ \\
\hline 3 & Cereais em grãos não especificados & 4,4 & $2,6^{* *}$ & $4,9^{*}$ \\
\hline 4 & Vegetais, frutas e nozes & 4,4 & $3,7^{\star *}$ & $5,4^{* * *}$ \\
\hline 5 & Sementes oleaginosas & 4,4 & $4,9^{* *}$ & $5,5^{\star * *}$ \\
\hline 7 & Fibras de plantas & 4,4 & $5^{* *}$ & $13,7^{\star *}$ \\
\hline 8 & Outras culturas não especificadas & 4,4 & $6,5^{\star *}$ & $6,8^{\star * *}$ \\
\hline 9 & Bovinos, ovinos, caprinos e cavalos & 5,6 & $4^{\star \star}$ & $4,6^{* * *}$ \\
\hline 10 & Animais não especificados & 5,6 & $2,6^{* *}$ & $9,6^{* * *}$ \\
\hline 12 & Lã e seda & 4,4 & $12,9^{* *}$ & $13,5^{\star * *}$ \\
\hline 13 & Silvicultura & 5,6 & $5^{\star *}$ & $5,1^{* * *}$ \\
\hline 14 & Pesca & 5,6 & $2,5^{\star *}$ & $5,6^{* * *}$ \\
\hline 15 & Carvão & 5,6 & $6,1^{* *}$ & $-1,3(\mathrm{~ns})$ \\
\hline 16 & Petróleo & 5,6 & $10,4^{* *}$ & $-67,2(\mathrm{~ns})$ \\
\hline 17 & Gás natural & 5,6 & $34,4^{* *}$ & ne \\
\hline 18 & Minerais não especificados & 5,6 & $1,8^{* *}$ & $4,2^{\star * *}$ \\
\hline 19 & Carne bovina & 4,4 & $7,7^{* *}$ & $12,8^{* * *}$ \\
\hline 20 & Outras carnes não especificadas & 4,4 & $8,8^{\star *}$ & $6,1^{* * *}$ \\
\hline 21 & Óleos e gorduras vegetais & 4,4 & $6,6^{\star *}$ & $6,8^{* * *}$ \\
\hline 22 & Laticínios & 4,4 & $7,3^{* *}$ & $4,9^{* * *}$ \\
\hline 23 & Arroz beneficiado & 4,4 & $5,2^{\star *}$ & $4,2^{* * *}$ \\
\hline 24 & Açúcar & 4,4 & $5,4^{\star *}$ & $1,1(\mathrm{~ns})$ \\
\hline 25 & Outros produtos alimentares & 4,4 & $4,0^{\star *}$ & $5,8^{\star * *}$ \\
\hline 26 & Bebidas e fumo & 6,2 & $2,3^{\star *}$ & $5,4^{* * *}$ \\
\hline 27 & Têxteis & 4,4 & $7,5^{\star *}$ & $7,3^{* * *}$ \\
\hline 28 & Vestuário & 8,8 & $7,4^{\star *}$ & $5,6^{* * *}$ \\
\hline 29 & Produtos de couro & 8,8 & $8,1^{* *}$ & $6,0^{* * *}$ \\
\hline 30 & Produtos de madeira & 5,6 & $6,8^{\star *}$ & $4,3^{* * *}$ \\
\hline 31 & Papel e gráfica & 3,6 & $5,9^{* *}$ & $6,0^{* * *}$ \\
\hline 32 & Refino de petróleo e carvão & 3,8 & $4,2^{\star *}$ & $7,3^{* * *}$ \\
\hline 33 & Química, borracha e produtos plásticos & 3,8 & $6,6^{* *}$ & $6,7^{\star * *}$ \\
\hline 34 & Produtos minerais & 5,6 & $5,8^{\star *}$ & $5,5^{\star * *}$ \\
\hline 35 & Metais ferrosos & 5,6 & $5,9^{* *}$ & $6,5^{* * *}$ \\
\hline 36 & Metais não especificados & 5,6 & $8,4^{* *}$ & $8,6^{* * *}$ \\
\hline 37 & Produtos de metais & 5,6 & $7,5^{\star *}$ & $6,3^{* * *}$ \\
\hline 38 & Veículos automotores, partes e peças & 10,4 & $5,6^{\star *}$ & $7,3^{* * *}$ \\
\hline 39 & Equipamentos de transporte não especificados & 10,4 & $8,6^{* *}$ & $8,8^{* * *}$ \\
\hline 40 & Equipamento eletrônico & 5,6 & $8,8^{\star *}$ & $6,6^{* * *}$ \\
\hline 41 & Máquinas e equipamento não especificados & 5,6 & $8,1^{* *}$ & $7,6^{* * *}$ \\
\hline \multirow[t]{6}{*}{42} & Outros manufaturados não especificados & 5,6 & $7,5^{* *}$ & $4,9^{* * *}$ \\
\hline & Média (1) & 5,4 & 6,1 & 6,9 \\
\hline & Mediana (1) & 5,0 & 6,2 & 6,2 \\
\hline & Mínimo (1) & 3,6 & 1,8 & 4,2 \\
\hline & Máximo (1) & 10,4 & 12,9 & 13,7 \\
\hline & Desvio-padrão $^{1}$ & 1,7 & 2,4 & 2,5 \\
\hline
\end{tabular}

Notas: $\left.{ }^{*}\right)$ significante no nível de $\left.10 \% ;{ }^{* *}\right)$ significante no nível de $\left.5 \% ;{ }^{* * *}\right)$ significante no nível de $1 \%$; ns = não significante; ne = não estimado devido a observações insuficientes. (1) Exclui os setores trigo, carvão, petróleo, gás natural e açúcar.

Fonte: Colunas (a) e (b) elaboradas com base em Hertel et al. (2007, p. 622). Coluna (c), elaboração própria. 
Não foi possível obter estimativas estatisticamente significantes para cinco setores: trigo, carvão, petróleo, gás natural e açúcar. Excluindo-se estes setores, a média simples das elasticidades é de 6,9, bastante próxima àquela obtida por Hertel et al. (2007), de 6,1 e as medianas são idênticas. Com relação às elasticidades adotadas no Gtap, em 23 setores as elasticidades obtidas são maiores, em 11 menores e em 1 setor, igual.

Por último, ilustra-se a importância das elasticidades de substituição específicas para o Brasil calculando-se o desvio de comércio nas importações brasileiras decorrentes de um eventual acordo de livre comércio com a UE. Para fins de comparação, o mesmo cálculo do desvio de comércio é efetuado utilizando-se as elasticidades do Gtap e de Hertel et al. (2007).

O desvio de comércio mede o incremento nas importações decorrente da substituição das importações de fornecedores extra-UE pelas de seu parceiro europeu, a preços maiores, podendo ser representado da seguinte forma (supondo também elasticidade de exportação europeia infinita):

$$
D C_{i}=\frac{\text { Mue }_{i} \operatorname{Mrm}_{i} E S_{i} \Delta\left(\text { Pue }_{i} / \operatorname{Pr} m_{i}\right)}{{M u e_{i}}+M_{i}+\operatorname{Mue}_{i} E S_{i} \Delta\left(\operatorname{Pue}_{i} / \operatorname{Pr} m_{i}\right)}
$$

Onde:

$D C_{i}=$ desvio de comércio do setor $i$;

$M_{u} e_{i}=$ importações da UE do setor $i$;

$\mathrm{Mrm}_{i}=$ importações do resto do mundo do setor $i$;

$E S_{i}=$ ES do setor $i$;

$P_{u} e_{i}=$ preço das importações do setor $i$ provenientes da UE; e

$\operatorname{Prm}_{i}=$ preço das importações do setor $i$ originárias do resto do mundo.

A variação do preço relativo é medida da seguinte forma:

$$
\Delta\left(\frac{\text { Pue }_{i}}{\text { Prm }_{i}}\right)=\frac{t_{p i}}{\left(1+t_{p i}\right)}
$$

Onde $t p_{i}$ representa a tarifa efetivamente paga no setor $i$ nas importações provenientes da UE.

Pode-se notar que a redução da tarifa exclusivamente sobre o os produtos provenientes da UE altera o preço relativo em relação às importações do resto mundo, que, multiplicado pela ES, e considerada a proporção das importações da UE e dos demais fornecedores do resto do mundo, provoca uma mudança em favor das importações europeias. Portanto, a ES desempenha um papel crucial no cálculo do desvio de comércio. 
A Tabela 6 apresenta as estimativas do desvio de comércio nas importações brasileiras provenientes da UE, segundo as elasticidades adotadas pelo Gtap e as estimadas por Hertel et al. (2007) e neste trabalho.

Tabela 6 - Estimativa do desvio de comércio da UE, segundo ES: Gtap, Hertel et al. (2007) e nossa estimativa (em US\$ milhões)

\begin{tabular}{|c|c|c|c|c|c|c|}
\hline Gtap & Descrição & $\begin{array}{c}\text { ES - Gtap } \\
\text { (a) }\end{array}$ & $\begin{array}{c}\text { ES - Hertel } \\
\text { (b) }\end{array}$ & $\begin{array}{c}\text { ES - estimado } \\
\text { (c) }\end{array}$ & $\begin{array}{c}\text { Coluna }(\mathbf{d})= \\
(\mathrm{c})-(\mathrm{a})\end{array}$ & $\begin{array}{c}\text { Coluna }(e)= \\
(\mathbf{c})-(\mathbf{b})\end{array}$ \\
\hline 1 & Arroz & 0 & 0 & 0 & 0 & 0 \\
\hline 4 & Vegetais, frutas e nozes & 9 & 8 & 11 & 2 & 3 \\
\hline 5 & Sementes oleaginosas & 0 & 0 & 0 & 0 & 0 \\
\hline 7 & Fibras de plantas & 0 & 1 & 2 & 2 & 1 \\
\hline 8 & Outras culturas & 1 & 2 & 2 & 1 & 0 \\
\hline 9 & Bovinos, ovinos, caprinos & 0 & 0 & 0 & 0 & 0 \\
\hline 10 & Animais não especificados & 3 & 2 & 5 & 2 & 3 \\
\hline 12 & Lã e seda & 0 & 0 & 0 & 0 & 0 \\
\hline 13 & Silvicultura & 0 & 0 & 0 & 0 & 0 \\
\hline 14 & Pesca & 0 & 0 & 0 & 0 & 0 \\
\hline 18 & Minerais não especificados & 2 & 1 & 1 & -1 & 0 \\
\hline 19 & Carne bovina & 0 & 0 & 0 & 0 & 0 \\
\hline 20 & Outras carnes & 0 & 0 & 0 & 0 & 0 \\
\hline 21 & Óleos e gorduras vegetais & 9 & 12 & 12 & 3 & 0 \\
\hline 22 & Laticínios & 8 & 12 & 9 & 1 & -3 \\
\hline 23 & Arroz beneficiado & 0 & 0 & 0 & 0 & 0 \\
\hline 25 & Outros produtos alimentares & 34 & 31 & 43 & 9 & 12 \\
\hline 26 & Bebidas e fumo & 49 & 22 & 44 & -5 & 22 \\
\hline 27 & Têxteis & 50 & 80 & 78 & 28 & -2 \\
\hline 28 & Vestuário & 25 & 22 & 17 & -8 & -5 \\
\hline 29 & Produtos de couro & 12 & 12 & 9 & -3 & -3 \\
\hline 30 & Produtos de madeira & 3 & 4 & 3 & 0 & -1 \\
\hline 31 & Papel e gráfica & 25 & 37 & 38 & 13 & 1 \\
\hline 32 & Refino de petróleo e carvão & 3 & 4 & 6 & 3 & 2 \\
\hline 33 & Química, borracha e plásticos & 495 & 798 & 808 & 313 & 10 \\
\hline 34 & Produtos minerais & 35 & 36 & 35 & 0 & -1 \\
\hline 35 & Metais ferrosos & 71 & 74 & 80 & 9 & 6 \\
\hline 36 & Outros metais & 31 & 43 & 44 & 13 & 1 \\
\hline 37 & Produtos de metais & 137 & 173 & 151 & 14 & -22 \\
\hline 38 & Veículos, partes e peças & 711 & 441 & 545 & -166 & 104 \\
\hline 39 & Outros equipamentos de transporte & 20 & 17 & 18 & -2 & 1 \\
\hline 40 & Equipamento eletrônico & 134 & 201 & 155 & 21 & -46 \\
\hline 41 & Máquinas e equipamentos & 956 & 1.282 & 1.221 & 265 & -61 \\
\hline \multirow[t]{2}{*}{42} & Produtos diversos & 23 & 29 & 21 & -2 & -8 \\
\hline & Total & 2.849 & 3.344 & 3.357 & 508 & 13 \\
\hline
\end{tabular}


O desvio de comércio total utilizando as elasticidades estimadas neste trabalho atinge US\$ 3,3 bilhões contra US\$ 2,8 bilhões com base nas elasticidades adotadas no Gtap. As maiores diferenças setoriais ocorrem em Química, borracha e produtos plásticos (US\$ 313 milhões), Máquinas e equipamentos (US\$ 265 milhões), Veículos, partes e peças (US\$ 166 milhões) e Têxteis (US\$ 28 milhões).

Com relação ao desvio de comércio calculado com as elasticidades de Hertel et al. (2007), os valores totais são aproximadamente similares. No entanto, o uso de elasticidades específicas para o Brasil pode gerar diferenças importantes para alguns setores: Veículos, partes e peças (US\$ 104 milhões), Máquinas e equipamentos (US\$ 61 milhões), Bebidas e fumo (US\$ 22 milhões) e Outros produtos alimentares (US\$ 12 milhões).

\section{CONCLUSÃO}

Este trabalho estimou as ES das importações do Brasil para 42 setores da matriz de insumo produto de 2005, destacando as diferenças nos custos de transporte e na tarifa efetivamente paga entre os produtos, segundo os países de procedência. As elasticidades obtidas são significativas a $1 \%$ para 39 setores, com média simples de 6,6 e amplitude de 4,7 e 13,7 .

Quando se utiliza a classificação setorial do Gtap, as elasticidades estimadas são similares às de Hertel et al. (2007), que adotam a mesma metodologia para obter estas elasticidades para um conjunto de seis países. Entretanto, o mesmo não ocorre em relação às elasticidades adotadas no Gtap. Em ambas as comparações, alguns setores apresentam diferenças acentuadas.

Em resumo, a disponibilidade das ES próprias para o Brasil permitirá obter cálculos mais precisos dos impactos sobre as importações provocados por uma eventual participação brasileira em novos acordos de liberalização comercial.

Por último, espera-se que este trabalho estimule novas estimativas das elasticidades de substituição das importações no Brasil na medida em que dados mais recentes fiquem disponíveis. O procedimento metodológico adotado neste trabalho é útil também para estimar a elasticidade de substituição entre as vendas domésticas e as exportações, parâmetro de fundamental importância para calcular os ganhos nas exportações nos cenários de liberalização comercial, mas não disponível atualmente. 


\section{REFERÊNCIAS}

AZEVEDO, A. F. Z. Mercosul: o impacto da liberalização preferencial e as perspectivas para a união aduaneira. Pesquisa e Planejamento Econômico, v. 38, n. 1, abr. 2008.

BARROSO, J. B. R. B. “Gains from imported varieties in the Brazilian economy”. In: BARROSO, J. B. R. B. Essays on international prices and the subjacent market structure. Tese de Doutorado, Escola de Pós-Graduação em Economia, Fundação Getulio Vargas, Rio de Janeiro, 2010. Disponível em: <http://epge.fgv.br/pt/pesquisa/teses-dissertacoes>. Acesso em: 15 jan. 2014.

BATISTA, J. C. Livre-comércio de produtos manufaturados entre o Brasil e a União Européia. In: TIRONI, L. F.; ABREU, M. P. (Orgs.) Aspectos estratégicos da política comercial brasileira. Brasília: Ipea-IPRI, 2001. vol. 1.

BLONINGEN, B. A.; WILSON, W. W. Explaining Armington: what determines substitutability between home and foreign goods? Canadian Journal of Economics, v. 32, n. 1, Feb. 1999.

CARVALHO, A.; PARENTE, A. Trade impact of the free trade of the Americas. In: IPEA (Ed.) Brazil, Mercosur and the Free Trade Area of the Americas. Brasília: IPEA, 2000.

CLINE, W. R. Trade negotiations in the Tokyo Round: a quantitative assessment. Washington, D. C.: The Brookings Institution, 1978.

CURY, S.; COELHO, A. M.; CORSEUIL, C. H. A computable general equilibrium model to analyze distributive aspects in Brazil with a trade policy illustration. Estudos Econômicos, v. 35, n. 4, out./dez. 2005.

FEENSTRA, R. C. New product varieties and the measurement of international prices. American Economic Review, v. 84, n. 1, 1994.

GURGEL, A. C. Impactos da liberalização comercial de produtos do agronegócio na rodada de Doha. Revista Brasileira de Economia, v. 60, n. 2, abr./jun. 2006.

HARRISON, G. W.; RUTHERFORD, T. F.; TARR, D. G.; GURGEL, A. Políticas de comércio regionais, multilaterais e unilaterais do Mercosul para o crescimento econômico e a redução da pobreza no Brasil. Pesquisa e Planejamento Econômico, Rio de Janeiro, v. 33, n. 1, abr. 2003.

HERTEL, T.; HUMMELS, D.; IVANIC, M.; KEENEY, R. How confident can we be of CGE-based assessments of Free Trade Agreements? Economic Modelling, v. 24, n. 4, 2007.

HUMMELS, D. Toward a geography of trade costs. Indiana - US: Purdue University, Sept. 2001.

INSTITUTO BRASILEIRO DE GEOGRAFIA E ESTATÍSTICA (IBGE). Matriz de insumo-produto: Brasil 2005. [on-line] Disponível em: <http://www.ibge.gov.br>. Acesso em: 11 abr. 2011.

IMBS, J.; MEJEAN, I. Elasticity optimism. Cahier, n. 2009-05, Departement D’Economie, Ecole Polytechnique, Févr. 2009. Disponível em: <http://www.economie.polytechnique.edu/ accueil/recherche/publications/cahiers-de-recherche>. Acesso em: 15 dez. 2013.

LAIRD, S.; YEATS, A. The UNCTAD trade policy simulation model. Discussion Papers, UNCTAD, n. 19, 1986.

KUME, H.; PIANI, G. ALCA: uma estimativa do impacto no comércio bilateral Brasil-Estados Unidos. Economia e Sociedade, v. 14, n. 2, jul./dez. 2005. 
KUME, H.; PIANI, G. Fluxos bilaterais de comércio e blocos regionais: uma aplicação do modelo gravitacional. Pesquisa e Planejamento Econômico, Rio de Janeiro, v. 30, n. 1, abr. 2000.

TOURINHO, O. A. F.; KUME, H.; PEDROSO, A. C. Elasticidade de Armington para o Brasil: 1986-2002. Revista Brasileira de Economia, v. 61, n. 2, abr./jun. 2007.

UNITED NATIONS CONFERENCE ON TRADE AND DEVELOPMENT (UNCTAD); WORLD BANK. Smart - Software for Market Analysis and Restrictions on Trade. [on-line] 1989. Disponível em: <https://wits.worldbank.org>. Acesso em: 15 dez. 2013. 


\section{Apêndice A - Resultados por setor da matriz de insumo produto do IBGE}

Equação estimada:

$$
\operatorname{LnVM} M_{i r}=a_{0}+a_{i r}+a_{1} \text { LnCusto }+a_{2} D_{\text {ano }}+e_{i r}
$$

Onde:

$$
\text { Custo }=1+C T_{i r}+T_{i r}+C T_{i r}{ }^{\star} T_{i r}
$$

Método de estimação: mínimos quadrados ordinários.

Os valores entre parênteses correspondem ao erro padrão robusto.

\begin{tabular}{|c|c|c|c|}
\hline Código/setor & Coluna1 & Coluna2 & Coluna3 \\
\hline \multicolumn{4}{|c|}{101 - Agricultura, silvicultura, exploração florestal } \\
\hline $\begin{array}{l}\mathrm{a} 0 \\
\text { (constante) } \\
\end{array}$ & $\begin{array}{l}11,06 \\
(0,14) \\
\end{array}$ & $\begin{array}{l}10,96 \\
(0,13) \\
\end{array}$ & $\begin{array}{l}11,18 \\
(0,13) \\
\end{array}$ \\
\hline $\begin{array}{l}\text { al } \\
\operatorname{Ln} \text { (Custo) }\end{array}$ & $\begin{array}{c}-4,70 \\
(0,45) \\
\end{array}$ & $\begin{array}{c}-4,84 \\
(0,39) \\
\end{array}$ & $\begin{array}{c}4,96 \\
(0,38) \\
\end{array}$ \\
\hline $\begin{array}{l}\text { a2 } \\
\text { (Dano) } \\
\end{array}$ & $\begin{array}{c}0,29 \\
(0,15) \\
\end{array}$ & $\begin{array}{c}0,25 \\
(0,14) \\
\end{array}$ & $\begin{array}{c}0,21 \\
(0,14) \\
\end{array}$ \\
\hline $\mathrm{R}^{2}$ ajustado & 20,6 & 19,9 & 20,6 \\
\hline $\mathrm{N}^{\circ}$ de observações & 1.352 & 1.292 & 1.310 \\
\hline $\mathrm{N}^{\circ}$ de países exportadores & 89 & 89 & 89 \\
\hline \multicolumn{4}{|l|}{102 - Pecuária e pesca } \\
\hline $\begin{array}{l}\text { a } 0 \\
\text { (constante) } \\
\end{array}$ & $\begin{array}{l}10,51 \\
(0,21) \\
\end{array}$ & $\begin{array}{l}10,97 \\
(0,22) \\
\end{array}$ & $\begin{array}{l}10,96 \\
(0,21) \\
\end{array}$ \\
\hline $\begin{array}{l}\text { Ln (Custo) } \\
\end{array}$ & $\begin{array}{c}-1,96 \\
(0,34) \\
\end{array}$ & $\begin{array}{c}-4,46 \\
(0,63) \\
\end{array}$ & $\begin{array}{c}-4,00 \\
(0,55) \\
\end{array}$ \\
\hline $\begin{array}{l}\text { a2 } \\
\text { (Dano) } \\
\end{array}$ & $\begin{array}{c}0,19 \\
(0,25) \\
\end{array}$ & $\begin{array}{c}0,23 \\
(0,25) \\
\end{array}$ & $\begin{array}{c}0,12 \\
(0,24) \\
\end{array}$ \\
\hline $\mathrm{R}^{2}$ ajustado & 22,3 & 20,1 & 21,0 \\
\hline $\mathrm{N}^{\circ}$ de observações & 327 & 301 & 297 \\
\hline $\mathrm{N}^{\circ}$ de países exportadores & 43 & 43 & 43 \\
\hline \multicolumn{4}{|l|}{201 - Petróleo e gás natural } \\
\hline $\begin{array}{l}\mathrm{a} 0 \\
\text { (constante) } \\
\end{array}$ & $\begin{array}{l}16,39 \\
(1,29) \\
\end{array}$ & $\begin{array}{c}\text { Número insuficiente } \\
\text { de observações }\end{array}$ & $\begin{array}{l}16,63 \\
(1,34) \\
\end{array}$ \\
\hline $\begin{array}{l}\text { al } \\
\operatorname{Ln} \text { (Custo) }\end{array}$ & $\begin{array}{c}0,20 \\
(2,72) \\
\end{array}$ & & $\begin{array}{c}0,21 \\
(2,82) \\
\end{array}$ \\
\hline $\begin{array}{l}\text { a2 } \\
\text { (Dano) }\end{array}$ & $\begin{array}{c}1,15 \\
(2,20) \\
\end{array}$ & & $\begin{array}{c}1,17 \\
(2,47)\end{array}$ \\
\hline $\mathrm{R}^{2}$ ajustado & 34,3 & & 7,1 \\
\hline $\mathrm{N}^{\circ}$ de observações & 39 & & 37 \\
\hline $\mathrm{N}^{\circ}$ de países exportadores & 25 & & 24 \\
\hline
\end{tabular}

A numeração das colunas segue a da Tabela 3. 


\begin{tabular}{|c|c|c|c|}
\hline Código/setor & Modelo 1 & Modelo 2 & Modelo 3 \\
\hline \multicolumn{4}{|l|}{202 - Minério de ferro } \\
\hline $\begin{array}{l}\mathrm{a} 0 \\
\text { (constante) }\end{array}$ & $\begin{array}{c}7,21 \\
(2,87)\end{array}$ & $\begin{array}{c}\text { Número } \\
\text { insuficiente de } \\
\text { observações }\end{array}$ & $\begin{array}{c}\text { Número } \\
\text { insuficiente de } \\
\text { observações }\end{array}$ \\
\hline $\begin{array}{l}\text { al } \\
\text { Ln(Custo) }\end{array}$ & $\begin{array}{c}-1,89 \\
(3,65) \\
\end{array}$ & & \\
\hline $\begin{array}{l}\text { a2 } \\
\text { (Dano) }\end{array}$ & $\begin{array}{c}1,84 \\
(1,50)\end{array}$ & & \\
\hline $\mathrm{R}^{2}$ ajustado & 86,6 & & \\
\hline$\underline{\mathrm{N}^{\circ} \text { de observações }}$ & 11 & & \\
\hline $\mathrm{N}^{\circ}$ de países exportadores & 8 & & \\
\hline \multicolumn{4}{|l|}{203 - Outros produtos extrativos } \\
\hline $\begin{array}{l}\mathrm{a} 0 \\
\text { (constante) }\end{array}$ & $\begin{array}{l}10,64 \\
(0,15)\end{array}$ & $\begin{array}{l}10,54 \\
(0,16)\end{array}$ & $\begin{array}{l}10,84 \\
(0,17)\end{array}$ \\
\hline $\begin{array}{l}\text { al } \\
\text { Ln(Custo) }\end{array}$ & $\begin{array}{l}-3,14 \\
(0,26)\end{array}$ & $\begin{array}{l}-3,47 \\
(0,42)\end{array}$ & $\begin{array}{l}-3,81 \\
(0,43)\end{array}$ \\
\hline $\begin{array}{l}\text { a2 } \\
\text { (Dano) } \\
\end{array}$ & $\begin{array}{c}0,40 \\
(0,18) \\
\end{array}$ & $\begin{array}{c}0,40 \\
(0,17) \\
\end{array}$ & $\begin{array}{c}0,38 \\
(0,17) \\
\end{array}$ \\
\hline $\mathrm{R}^{2}$ ajustado & 26,1 & 18,5 & 19,6 \\
\hline $\mathrm{N}^{\circ}$ de observações & 1.119 & 1.026 & 1.043 \\
\hline No de países exportadores & 82 & 79 & 79 \\
\hline \multicolumn{4}{|l|}{301 - Alimentos e Bebidas } \\
\hline $\begin{array}{l}\text { a0 } \\
\text { (constante) } \\
\end{array}$ & $\begin{array}{l}10,55 \\
(0,73) \\
\end{array}$ & $\begin{array}{l}10,97 \\
(0,07)\end{array}$ & $\begin{array}{l}11,01 \\
(0,07) \\
\end{array}$ \\
\hline $\begin{array}{l}\text { al } \\
\text { Ln(Custo) } \\
\end{array}$ & $\begin{array}{c}-3,13 \\
(0,25) \\
\end{array}$ & $\begin{array}{l}-5,16 \\
(0,21) \\
\end{array}$ & $\begin{array}{c}5,04 \\
(0,21) \\
\end{array}$ \\
\hline $\begin{array}{l}\text { a2 } \\
\text { (Dano) } \\
\end{array}$ & $\begin{array}{c}1,70 \\
(0,07) \\
\end{array}$ & $\begin{array}{c}0,11 \\
(0,07) \\
\end{array}$ & $\begin{array}{c}0,12 \\
((0,07) \\
\end{array}$ \\
\hline $\mathrm{R}^{2}$ ajustado & 24,8 & 24,5 & 24,0 \\
\hline $\mathrm{N}^{\circ}$ de observações & 5.420 & 5.258 & 5.234 \\
\hline $\mathrm{N}^{\circ}$ de países exportadores & 103 & 102 & 102 \\
\hline \multicolumn{4}{|l|}{302 - Produtos do fumo } \\
\hline $\begin{array}{l}\mathrm{a} 0 \\
\text { (constante) } \\
\end{array}$ & $\begin{array}{l}11,36 \\
(0,36) \\
\end{array}$ & $\begin{array}{l}11,88 \\
(0,35) \\
\end{array}$ & $\begin{array}{l}11,75 \\
(0,34) \\
\end{array}$ \\
\hline $\begin{array}{l}\text { al } \\
\text { Ln(Custo) }\end{array}$ & $\begin{array}{c}4,38 \\
(1,06) \\
\end{array}$ & $\begin{array}{c}-5,79 \\
(1,04) \\
\end{array}$ & $\begin{array}{c}5,57 \\
(1,04) \\
\end{array}$ \\
\hline $\begin{array}{l}\text { a2 } \\
\text { (Dano) } \\
\end{array}$ & $\begin{array}{c}0,29 \\
(0,36) \\
\end{array}$ & $\begin{array}{c}0,14 \\
(0,35) \\
\end{array}$ & $\begin{array}{c}0,33 \\
(0,34) \\
\end{array}$ \\
\hline $\mathrm{R}^{2}$ ajustado & 68,3 & 49,1 & 49,0 \\
\hline No. de observações & 131 & 129 & 128 \\
\hline $\mathrm{N}^{\circ}$ de países exportadores & 41 & 40 & 40 \\
\hline \multicolumn{4}{|l|}{303 - Têxteis } \\
\hline $\begin{array}{l}\text { a0 } \\
\text { (constante) }\end{array}$ & $\begin{array}{c}9,80 \\
(0,10) \\
\end{array}$ & $\begin{array}{l}10,55 \\
(0,06) \\
\end{array}$ & $\begin{array}{l}10,49 \\
(0,06) \\
\end{array}$ \\
\hline $\begin{array}{l}\text { al } \\
\text { Ln(Custo) }\end{array}$ & $\begin{array}{l}-3,58 \\
(0,36) \\
\end{array}$ & $\begin{array}{c}-6,11 \\
(0,17) \\
\end{array}$ & $\begin{array}{c}5,99 \\
(0,17) \\
\end{array}$ \\
\hline $\begin{array}{l}\text { a2 } \\
\text { (Dano) }\end{array}$ & $\begin{array}{c}0,48 \\
(0,06) \\
\end{array}$ & $\begin{array}{c}0,48 \\
(0,05) \\
\end{array}$ & $\begin{array}{c}0,45 \\
(0,05) \\
\end{array}$ \\
\hline $\mathrm{R}^{2}$ ajustado & 19,6 & 20,7 & 20,1 \\
\hline $\mathrm{N}^{\circ}$ de observações & 8.114 & 7.889 & 7.832 \\
\hline $\mathrm{N}^{\circ}$ de países exportadores & 116 & 116 & 114 \\
\hline \multicolumn{4}{|c|}{304 - Artigos do vestuário e acessórios } \\
\hline $\begin{array}{l}\text { a0 } \\
\text { (constante) }\end{array}$ & $\begin{array}{c}8,72 \\
(0,10) \\
\end{array}$ & $\begin{array}{c}9,05 \\
(0,07) \\
\end{array}$ & $\begin{array}{c}9,00 \\
(0,07) \\
\end{array}$ \\
\hline
\end{tabular}




\begin{tabular}{|c|c|c|c|}
\hline Código/setor & Modelo 1 & Modelo 2 & Modelo 3 \\
\hline $\begin{array}{l}\text { al } \\
\text { Ln(Custo) }\end{array}$ & $\begin{array}{r}-3,80 \\
(0,37) \\
\end{array}$ & $\begin{array}{c}-4,67 \\
(0,22) \\
\end{array}$ & $\begin{array}{r}-4,59 \\
(0,22) \\
\end{array}$ \\
\hline $\begin{array}{l}\mathrm{a} 2 \\
\text { (Dano) }\end{array}$ & $\begin{array}{c}0,50 \\
(0,06) \\
\end{array}$ & $\begin{array}{c}0,48 \\
(0,06) \\
\end{array}$ & $\begin{array}{c}0,43 \\
(0,06) \\
\end{array}$ \\
\hline $\mathrm{R}^{2}$ ajustado & 26,2 & 25,7 & 24,0 \\
\hline $\mathrm{N}^{\circ}$ de observações & 6.359 & 6.244 & 6.174 \\
\hline $\mathrm{N}^{\circ}$ de países exportadores & 113 & 110 & 110 \\
\hline \multicolumn{4}{|c|}{305 - Artefatos de couro e calçados } \\
\hline $\begin{array}{l}\mathrm{a} 0 \\
\text { (constante) }\end{array}$ & $\begin{array}{l}10,01 \\
(0,13) \\
\end{array}$ & $\begin{array}{l}10,34 \\
(0,10) \\
\end{array}$ & $\begin{array}{l}10,37 \\
(0,10)\end{array}$ \\
\hline $\begin{array}{l}\text { al } \\
\text { Ln(Custo) }\end{array}$ & $\begin{array}{c}-4,00 \\
(0,46) \\
\end{array}$ & $\begin{array}{l}-5,03 \\
(0,31) \\
\end{array}$ & $\begin{array}{c}-4,98 \\
(0,31) \\
\end{array}$ \\
\hline $\begin{array}{l}\mathrm{a} 2 \\
\text { (Dano) }\end{array}$ & $\begin{array}{c}0,31 \\
(0,11) \\
\end{array}$ & $\begin{array}{c}0,28 \\
(0,10) \\
\end{array}$ & $\begin{array}{c}0,21 \\
(0,10) \\
\end{array}$ \\
\hline $\mathrm{R}^{2}$ ajustado & 33,1 & 32,6 & 32,9 \\
\hline $\mathrm{N}^{\circ}$ de observações & 2.125 & 2.071 & 2.048 \\
\hline $\mathrm{N}^{\circ}$ de países exportadores & 97 & 96 & 96 \\
\hline \multicolumn{4}{|l|}{306 - Produtos de madeira } \\
\hline $\begin{array}{l}\text { a0 } \\
\text { (constante) }\end{array}$ & $\begin{array}{c}9,08 \\
(0,15) \\
\end{array}$ & $\begin{array}{c}9,44 \\
(0,16) \\
\end{array}$ & $\begin{array}{c}9,40 \\
(0,16) \\
\end{array}$ \\
\hline $\begin{array}{l}\text { al } \\
\text { Ln(Custo) }\end{array}$ & $\begin{array}{c}-3,05 \\
(0,38) \\
\end{array}$ & $\begin{array}{c}-4,02 \\
(0,42) \\
\end{array}$ & $\begin{array}{c}-4,00 \\
(0,42) \\
\end{array}$ \\
\hline $\begin{array}{l}\text { a2 } \\
\text { (Dano) } \\
\end{array}$ & $\begin{array}{c}0,51 \\
(0,17) \\
\end{array}$ & $\begin{array}{c}0,48 \\
(0,16) \\
\end{array}$ & $\begin{array}{c}0,45 \\
(0,16)\end{array}$ \\
\hline $\mathrm{R}^{2}$ ajustado & 24,6 & 22,6 & 22,7 \\
\hline $\mathrm{N}^{\circ}$ de observações & 1.031 & 988 & 982 \\
\hline $\mathrm{N}^{\circ}$ de países exportadores & 74 & 72 & 72 \\
\hline Código/setor & Modelo 1 & Modelo 2 & Modelo 3 \\
\hline \multicolumn{4}{|c|}{307 - Celulose e produtos de papel } \\
\hline $\begin{array}{l}\text { a0 } \\
\text { (constante) }\end{array}$ & $\begin{array}{c}9,84 \\
(0,11) \\
\end{array}$ & $\begin{array}{l}10,56 \\
(0,11) \\
\end{array}$ & $\begin{array}{l}10,47 \\
(0,11)\end{array}$ \\
\hline $\begin{array}{l}\text { al } \\
\text { Ln(Custo) }\end{array}$ & $\begin{array}{c}-3,24 \\
(0,27) \\
\end{array}$ & $\begin{array}{c}-5,37 \\
(0,27) \\
\end{array}$ & $\begin{array}{c}-5,30 \\
(0,28)\end{array}$ \\
\hline $\begin{array}{l}\text { a2 } \\
\text { (Dano) } \\
\end{array}$ & $\begin{array}{c}0,36 \\
(0,11) \\
\end{array}$ & $\begin{array}{c}0,33 \\
(0,10) \\
\end{array}$ & $\begin{array}{c}0,29 \\
(0,11) \\
\end{array}$ \\
\hline $\mathrm{R}^{2}$ ajustado & 25,4 & 23,9 & 24,1 \\
\hline $\mathrm{N}^{\circ}$. de observações & 2.997 & 2.810 & 2.833 \\
\hline $\mathrm{N}^{\circ}$. países exportadores & 82 & 78 & 79 \\
\hline \multicolumn{4}{|l|}{308 - Jornais, revistas, discos } \\
\hline $\begin{array}{l}\mathrm{a} 0 \\
\text { (constante) }\end{array}$ & $\begin{array}{c}9,00 \\
(0,12) \\
\end{array}$ & $\begin{array}{c}9,74 \\
(0,14) \\
\end{array}$ & $\begin{array}{c}9,49 \\
(0,15) \\
\end{array}$ \\
\hline $\begin{array}{l}\text { al } \\
\text { Ln(Custo) }\end{array}$ & $\begin{array}{c}-2,58 \\
(0,18) \\
\end{array}$ & $\begin{array}{c}-4,13 \\
(0,37) \\
\end{array}$ & $\begin{array}{c}-4,03 \\
(0,39) \\
\end{array}$ \\
\hline $\begin{array}{l}\text { a2 } \\
\text { (Dano) } \\
\end{array}$ & $\begin{array}{c}0,38 \\
(0,15) \\
\end{array}$ & $\begin{array}{c}0,22 \\
(0,14) \\
\end{array}$ & $\begin{array}{c}0,30 \\
(0,15) \\
\end{array}$ \\
\hline $\mathrm{R}^{2}$ ajustado & 33,9 & 26,8 & 26,0 \\
\hline $\mathrm{N}^{\circ}$ de observações & 1.378 & 1.262 & 1.281 \\
\hline $\mathrm{N}^{\circ}$ de países exportadores & 82 & 80 & 81 \\
\hline \multicolumn{4}{|l|}{309 - Refino de petróleo e coque } \\
\hline $\begin{array}{l}\mathrm{a} 0 \\
\text { (constante) }\end{array}$ & $\begin{array}{l}12,06 \\
(0,21)\end{array}$ & $\begin{array}{l}11,41 \\
(0,21) \\
\end{array}$ & $\begin{array}{l}12,22 \\
(0,21) \\
\end{array}$ \\
\hline $\begin{array}{l}\text { al } \\
\text { Ln(Custo) }\end{array}$ & $\begin{array}{c}-5,47 \\
(0,59) \\
\end{array}$ & $\begin{array}{c}-5,30 \\
(0,65) \\
\end{array}$ & $\begin{array}{c}-6,44 \\
(0,69) \\
\end{array}$ \\
\hline
\end{tabular}




\begin{tabular}{|c|c|c|c|}
\hline Código/setor & Modelo 1 & Modelo 2 & Modelo 3 \\
\hline $\begin{array}{l}\text { a2 } \\
\text { (Dano) }\end{array}$ & $\begin{array}{c}0,41 \\
(0,25) \\
\end{array}$ & $\begin{array}{c}0,11 \\
(0,24) \\
\end{array}$ & $\begin{array}{c}0,41 \\
(0,24) \\
\end{array}$ \\
\hline $\mathrm{R}^{2}$ ajustado & 34,2 & 26,3 & 33,2 \\
\hline $\mathrm{N}^{\circ}$ de observações & 749 & 641 & 726 \\
\hline $\mathrm{N}^{\circ}$ de países exportadores & 69 & 63 & 68 \\
\hline \multicolumn{4}{|l|}{310 - Álcool } \\
\hline $\begin{array}{l}\mathrm{a} 0 \\
\text { (constante) }\end{array}$ & $\begin{array}{c}9,73 \\
(1,04) \\
\end{array}$ & $\begin{array}{c}9,76 \\
(1,05) \\
\end{array}$ & $\begin{array}{l}10,03 \\
(0,96) \\
\end{array}$ \\
\hline $\begin{array}{l}\text { al } \\
\text { Ln(Custo) }\end{array}$ & $\begin{array}{c}-2,25 \\
(4,49) \\
\end{array}$ & $\begin{array}{c}2,26 \\
(4,41) \\
\end{array}$ & $\begin{array}{c}5,92 \\
(3,09) \\
\end{array}$ \\
\hline $\begin{array}{l}\text { a2 } \\
\text { (Dano) }\end{array}$ & $\begin{array}{c}-0,44 \\
(2,24)\end{array}$ & $\begin{array}{c}-0,45 \\
(2,22)\end{array}$ & $\begin{array}{c}1,84 \\
(1,35)\end{array}$ \\
\hline $\mathrm{R}^{2}$ ajustado & 34,3 & $-34,1$ & 33,3 \\
\hline $\mathrm{N}^{\circ}$ de observações & 23 & 23 & 21 \\
\hline $\mathrm{N}^{\circ}$ de países exportadores & 12 & 12 & 12 \\
\hline \multicolumn{4}{|l|}{311 - Produtos químicos } \\
\hline $\begin{array}{l}\mathrm{a} 0 \\
\text { (constante) }\end{array}$ & $\begin{array}{l}10,36 \\
(0,04)\end{array}$ & $\begin{array}{l}10,73 \\
(0,04)\end{array}$ & $\begin{array}{l}10,75 \\
(0,03)\end{array}$ \\
\hline $\begin{array}{l}\text { al } \\
\text { Ln(Custo) }\end{array}$ & $\begin{array}{c}-3,90 \\
(0,16)\end{array}$ & $\begin{array}{c}-6,19 \\
(0,12)\end{array}$ & $\begin{array}{c}-6,13 \\
(0,12)\end{array}$ \\
\hline $\begin{array}{l}\mathrm{a} 2 \\
\text { (Dano) }\end{array}$ & $\begin{array}{c}-0,04 \\
(0,04)\end{array}$ & $\begin{array}{c}-0,05 \\
(0,04)\end{array}$ & $\begin{array}{c}-0,05 \\
(0,04)\end{array}$ \\
\hline $\mathrm{R}^{2}$ ajustado & 17,4 & 17,9 & 17,6 \\
\hline No de observações & 18.284 & 17.530 & 17.450 \\
\hline $\mathrm{N}^{\circ}$ de países exportadores & 108 & 105 & 105 \\
\hline \multicolumn{4}{|c|}{312 - Fabricação de resina e elastômeros } \\
\hline $\begin{array}{l}\text { a0 } \\
\text { (constante) }\end{array}$ & $\begin{array}{l}11,16 \\
(0,07)\end{array}$ & $\begin{array}{l}12,05 \\
(0,07)\end{array}$ & $\begin{array}{l}12,12 \\
(0,07)\end{array}$ \\
\hline $\begin{array}{l}\text { al } \\
\text { Ln(Custo) }\end{array}$ & $\begin{array}{c}-4,28 \\
(0,26) \\
\end{array}$ & $\begin{array}{c}-6,23 \\
(0,21)\end{array}$ & $\begin{array}{c}-6,14 \\
(0,21)\end{array}$ \\
\hline $\begin{array}{l}\text { a } \\
\text { (Dano) }\end{array}$ & $\begin{array}{c}0,35 \\
(0,07) \\
\end{array}$ & $\begin{array}{c}0,27 \\
(0,07) \\
\end{array}$ & $\begin{array}{c}0,28 \\
(0,07) \\
\end{array}$ \\
\hline $\mathrm{R}^{2}$ ajustado & 26,8 & 26,6 & 26,4 \\
\hline $\mathrm{N}^{\circ}$ de observações & 4.574 & 4.404 & 4.402 \\
\hline $\mathrm{N}^{\circ}$ de países exportadores & 77 & 77 & 77 \\
\hline \multicolumn{4}{|l|}{313 - Produtos farmacêuticos } \\
\hline $\begin{array}{l}\mathrm{a} 0 \\
\text { (constante) }\end{array}$ & $\begin{array}{l}11,32 \\
(0,07) \\
\end{array}$ & $\begin{array}{l}11,38 \\
(0,06) \\
\end{array}$ & $\begin{array}{l}11,44 \\
(0,06)\end{array}$ \\
\hline $\begin{array}{l}\text { al } \\
\text { Ln(Custo) }\end{array}$ & $\begin{array}{c}-6,83 \\
(0,48)\end{array}$ & $\begin{array}{c}-7,57 \\
(0,31) \\
\end{array}$ & $\begin{array}{r}-7,57 \\
(0,31) \\
\end{array}$ \\
\hline (Dano) & $\begin{array}{c}0,30 \\
(0,08)\end{array}$ & $\begin{array}{c}0,33 \\
(0,08)\end{array}$ & $\begin{array}{c}0,36 \\
(0,08)\end{array}$ \\
\hline $\mathrm{R}^{2}$ ajustado & 13,3 & 13,2 & 13,5 \\
\hline $\mathrm{N}^{\circ}$ de observações & 5.247 & 5.019 & 5.006 \\
\hline $\mathrm{N}^{\circ}$ de países exportadores & 77 & 77 & 77 \\
\hline \multicolumn{4}{|l|}{314 - Defensivos agrícolas } \\
\hline $\begin{array}{l}\mathrm{a} 0 \\
\text { (constante) }\end{array}$ & $\begin{array}{l}12,80 \\
(0,29)\end{array}$ & $\begin{array}{l}12,91 \\
(0,25)\end{array}$ & $\begin{array}{l}13,21 \\
(0,25)\end{array}$ \\
\hline $\begin{array}{l}\text { al } \\
\text { Ln(Custo) }\end{array}$ & $\begin{array}{c}-9,00 \\
(1,72)\end{array}$ & $\begin{array}{r}-11,72 \\
(1,03) \\
\end{array}$ & $\begin{array}{r}-12,69 \\
(1,18)\end{array}$ \\
\hline $\begin{array}{l}\mathrm{a} 2 \\
\text { (Dano) }\end{array}$ & $\begin{array}{l}-0,27 \\
(0,29)\end{array}$ & $\begin{array}{c}0,00 \\
(0,28)\end{array}$ & $\begin{array}{c}0,05 \\
(0,27)\end{array}$ \\
\hline $\mathrm{R}^{2}$ ajustado & 32,4 & 38,3 & 38,9 \\
\hline $\mathrm{N}^{\circ}$ de observações & 524 & 469 & 485 \\
\hline
\end{tabular}




\begin{tabular}{|c|c|c|c|}
\hline Código/setor & Modelo 1 & Modelo 2 & Modelo 3 \\
\hline $\mathrm{N}^{\circ}$ de países exportadores & 45 & 45 & 45 \\
\hline \multicolumn{4}{|c|}{315 - Perfumaria, higiene e limpeza } \\
\hline $\begin{array}{l}\mathrm{a} 0 \\
\text { (constante) }\end{array}$ & $\begin{array}{l}10,59 \\
(0,13) \\
\end{array}$ & $\begin{array}{l}10,89 \\
(0,14) \\
\end{array}$ & $\begin{array}{l}10,87 \\
(0,13) \\
\end{array}$ \\
\hline $\begin{array}{l}\text { al } \\
\text { Ln(Custo) }\end{array}$ & $\begin{array}{c}-3,51 \\
(0,36) \\
\end{array}$ & $\begin{array}{c}-4,51 \\
(0,38) \\
\end{array}$ & $\begin{array}{c}-4,44 \\
(0,37) \\
\end{array}$ \\
\hline $\begin{array}{l}\mathrm{a} 2 \\
\text { (Dano) } \\
\end{array}$ & $\begin{array}{c}0,17 \\
(0,14) \\
\end{array}$ & $\begin{array}{c}0,24 \\
(0,13) \\
\end{array}$ & $\begin{array}{c}0,26 \\
(0,13) \\
\end{array}$ \\
\hline $\mathrm{R}^{2}$ ajustado & 33,2 & 25,5 & 24,9 \\
\hline $\mathrm{N}^{\circ}$ de observações & 1.336 & 1.292 & 1.281 \\
\hline $\mathrm{N}^{\circ}$ de países exportadores & 63 & 61 & 61 \\
\hline \multicolumn{4}{|c|}{316 - Tintas, vernizes, esmaltes e lacas } \\
\hline $\begin{array}{l}\mathrm{a} 0 \\
\text { (constante) }\end{array}$ & $\begin{array}{l}10,86 \\
(0,18)\end{array}$ & $\begin{array}{l}11,43 \\
(0,13)\end{array}$ & $\begin{array}{l}11,44 \\
(0,13)\end{array}$ \\
\hline $\begin{array}{l}\text { al } \\
\text { Ln(Custo) }\end{array}$ & $\begin{array}{c}-3,36 \\
(0,56) \\
\end{array}$ & $\begin{array}{c}-5,27 \\
(0,32) \\
\end{array}$ & $\begin{array}{r}-5,32 \\
(0,32) \\
\end{array}$ \\
\hline $\begin{array}{l}\text { a2 } \\
\text { (Dano) }\end{array}$ & $\begin{array}{c}0,24 \\
(0,14) \\
\end{array}$ & $\begin{array}{c}0,18 \\
(0,13)\end{array}$ & $\begin{array}{c}0,18 \\
(0,13)\end{array}$ \\
\hline $\mathrm{R}^{2}$ ajustado & 34,2 & 35,1 & 35,6 \\
\hline $\mathrm{N}^{\circ}$ de observações & 1.184 & 1.147 & 1.130 \\
\hline $\mathrm{N}^{\circ}$ de países exportadores & 57 & 55 & 55 \\
\hline \multicolumn{4}{|c|}{317 - Produtos e preparados químicos diversos } \\
\hline $\begin{array}{l}\mathrm{a} 0 \\
\text { (constante) } \\
\end{array}$ & $\begin{array}{l}10,69 \\
(0,08) \\
\end{array}$ & $\begin{array}{l}11,11 \\
(0,07) \\
\end{array}$ & $\begin{array}{l}11,10 \\
(0,07) \\
\end{array}$ \\
\hline $\begin{array}{l}\text { al } \\
\text { Ln(Custo) }\end{array}$ & $\begin{array}{c}-4,18 \\
(0,30) \\
\end{array}$ & $\begin{array}{c}-5,86 \\
(0,21) \\
\end{array}$ & $\begin{array}{c}5,71 \\
(0,21) \\
\end{array}$ \\
\hline $\begin{array}{l}\mathrm{a} 2 \\
\text { (Dano) }\end{array}$ & $\begin{array}{c}0,33 \\
(0,08) \\
\end{array}$ & $\begin{array}{c}0,29 \\
(0,07) \\
\end{array}$ & $\begin{array}{c}0,26 \\
(0,07) \\
\end{array}$ \\
\hline $\mathrm{R}^{2}$ ajustado & 24,6 & 23,5 & 23,3 \\
\hline $\mathrm{N}^{\circ}$ de observações & 4.770 & 4.621 & 4.589 \\
\hline $\mathrm{N}^{\circ}$ de países exportadores & 93 & 91 & 91 \\
\hline \multicolumn{4}{|c|}{318 - Artigos de borracha e plástico } \\
\hline $\begin{array}{l}\mathrm{a} 0 \\
\text { (constante) }\end{array}$ & $\begin{array}{l}10,46 \\
(0,06)\end{array}$ & $\begin{array}{l}10,88 \\
(0,06) \\
\end{array}$ & $\begin{array}{l}10,85 \\
(0,06) \\
\end{array}$ \\
\hline $\begin{array}{l}\text { al } \\
\text { Ln(Custo) }\end{array}$ & $\begin{array}{c}-3,79 \\
(0,17) \\
\end{array}$ & $\begin{array}{c}-4,93 \\
(0,18) \\
\end{array}$ & $\begin{array}{c}-4,91 \\
(0,18) \\
\end{array}$ \\
\hline $\begin{array}{l}\mathrm{a} 2 \\
\text { (Dano) }\end{array}$ & $\begin{array}{c}0,38 \\
(0,06) \\
\end{array}$ & $\begin{array}{c}0,34 \\
(0,06) \\
\end{array}$ & $\begin{array}{c}0,33 \\
(0,06) \\
\end{array}$ \\
\hline $\mathrm{R}^{2}$ ajustado & 25,8 & 23,9 & 23,6 \\
\hline $\mathrm{N}^{\circ}$ de observações & 7.307 & 7.023 & 7.000 \\
\hline $\mathrm{N}^{\circ}$ de países exportadores & 131 & 125 & 125 \\
\hline \multicolumn{4}{|l|}{319 - Cimento } \\
\hline $\begin{array}{l}\mathrm{a} 0 \\
\text { (constante) }\end{array}$ & $\begin{array}{c}9,82 \\
(0,34) \\
\end{array}$ & $\begin{array}{l}10,53 \\
(0,50)\end{array}$ & $\begin{array}{l}10,43 \\
(0,51)\end{array}$ \\
\hline $\begin{array}{l}\text { al } \\
\text { Ln(Custo) }\end{array}$ & $\begin{array}{c}-2,81 \\
(0,48) \\
\end{array}$ & $\begin{array}{c}-4,97 \\
(1,21)\end{array}$ & $\begin{array}{c}-5,08 \\
(1,18)\end{array}$ \\
\hline $\begin{array}{l}\mathrm{a} 2 \\
\text { (Dano) }\end{array}$ & $\begin{array}{c}0,36 \\
(0,44) \\
\end{array}$ & $\begin{array}{c}0,22 \\
(0,47)\end{array}$ & $\begin{array}{c}0,38 \\
(0,47)\end{array}$ \\
\hline $\mathrm{R}^{2}$ ajustado & 14,8 & 13,6 & 12,8 \\
\hline No. de observações & 190 & 181 & 178 \\
\hline $\mathrm{N}^{\circ}$ de países exportadores & 42 & 42 & 42 \\
\hline \multicolumn{4}{|c|}{320 - Outros produtos de minerais não-metálicos } \\
\hline $\begin{array}{l}\mathrm{a} 0 \\
\text { (constante) }\end{array}$ & $\begin{array}{c}9,88 \\
(0,09)\end{array}$ & $\begin{array}{l}10,27 \\
(0,08)\end{array}$ & $\begin{array}{l}10,22 \\
(0,07)\end{array}$ \\
\hline
\end{tabular}




\begin{tabular}{|c|c|c|c|}
\hline Código/setor & Modelo 1 & Modelo 2 & Modelo 3 \\
\hline $\begin{array}{l}\text { al } \\
\text { Ln(Custo) }\end{array}$ & $\begin{array}{c}-3,45 \\
(0,30)\end{array}$ & $\begin{array}{c}-4,51 \\
(0,20)\end{array}$ & $\begin{array}{c}-4,43 \\
(0,20)\end{array}$ \\
\hline $\begin{array}{l}\text { a2 } \\
\text { (Dano) } \\
\end{array}$ & $\begin{array}{c}0,41 \\
(0,07) \\
\end{array}$ & $\begin{array}{c}0,38 \\
(0,07) \\
\end{array}$ & $\begin{array}{c}0,36 \\
(0,07) \\
\end{array}$ \\
\hline $\mathrm{R}^{2}$ ajustado & 24,3 & 21,6 & 21,0 \\
\hline $\mathrm{N}^{\circ}$ de observações & 5.039 & 4.889 & 4.846 \\
\hline $\mathrm{N}^{\circ}$ de países exportadores & 95 & 95 & 93 \\
\hline \multicolumn{4}{|c|}{321 - Fabricação de aço e derivados } \\
\hline $\begin{array}{l}\text { a0 } \\
\text { (constante) } \\
\end{array}$ & $\begin{array}{l}10,70 \\
(0,09) \\
\end{array}$ & $\begin{array}{l}11,16 \\
(0,07) \\
\end{array}$ & $\begin{array}{l}11,14 \\
(0,07) \\
\end{array}$ \\
\hline $\begin{array}{l}\text { al } \\
\text { Ln(Custo) }\end{array}$ & $\begin{array}{c}-3,97 \\
(0,30) \\
\end{array}$ & $\begin{array}{l}5,68 \\
(0,25) \\
\end{array}$ & $\begin{array}{c}5,52 \\
(0,24) \\
\end{array}$ \\
\hline $\begin{array}{l}\text { a2 } \\
\text { (Dano) }\end{array}$ & $\begin{array}{c}0,61 \\
(0,08) \\
\end{array}$ & $\begin{array}{c}0,50 \\
(0,07) \\
\end{array}$ & $\begin{array}{c}0,47 \\
(0,07) \\
\end{array}$ \\
\hline $\mathrm{R}^{2}$ ajustado & 23,3 & 22,1 & 21,0 \\
\hline $\mathrm{N}^{\circ}$ de observações & 4.880 & 4.743 & 4.706 \\
\hline $\mathrm{N}^{\circ}$ de países exportadores & 90 & 90 & 90 \\
\hline \multicolumn{4}{|c|}{322 - Metalurgia de metais não-ferrosos } \\
\hline $\begin{array}{l}\mathrm{a} 0 \\
\text { (constante) }\end{array}$ & $\begin{array}{l}10,57 \\
(0,10) \\
\end{array}$ & $\begin{array}{l}11,01 \\
(0,08) \\
\end{array}$ & $\begin{array}{l}11,04 \\
(0,08) \\
\end{array}$ \\
\hline $\begin{array}{l}\text { a1 } \\
\operatorname{Ln}(\text { Custo }) \\
\end{array}$ & $\begin{array}{c}-4,86 \\
(0,43) \\
\end{array}$ & $\begin{array}{c}-6,94 \\
(0,31) \\
\end{array}$ & $\begin{array}{r}-6,98 \\
(0,31) \\
\end{array}$ \\
\hline $\begin{array}{l}\text { a2 } \\
\text { (Dano) }\end{array}$ & $\begin{array}{c}0,41 \\
(0,09) \\
\end{array}$ & $\begin{array}{c}0,28 \\
(0,09) \\
\end{array}$ & $\begin{array}{c}0,29 \\
(0,09)\end{array}$ \\
\hline $\mathrm{R}^{2}$ ajustado & 22,2 & 21,3 & 21,3 \\
\hline $\mathrm{N}^{\circ}$ de observações & 3.787 & 3.612 & 3.622 \\
\hline $\mathrm{N}^{\circ}$ de países exportadores & 102 & 99 & 99 \\
\hline Código/setor & Modelo 1 & Modelo 2 & Modelo 3 \\
\hline \multicolumn{4}{|l|}{323 - Produtos de metal } \\
\hline $\begin{array}{l}\text { a0 } \\
\text { (constante) }\end{array}$ & $\begin{array}{c}9,66 \\
(0,06) \\
\end{array}$ & $\begin{array}{l}10,20 \\
(0,06)\end{array}$ & $\begin{array}{l}10,11 \\
(0,06)\end{array}$ \\
\hline $\begin{array}{l}\text { al } \\
\text { Ln(Custo) }\end{array}$ & $\begin{array}{c}-3,92 \\
(0,19) \\
\end{array}$ & $\begin{array}{c}-5,43 \\
(0,19) \\
\end{array}$ & $\begin{array}{c}5,40 \\
(0,19) \\
\end{array}$ \\
\hline $\begin{array}{l}\text { a2 } \\
\text { (Dano) }\end{array}$ & $\begin{array}{c}0,31 \\
(0,06) \\
\end{array}$ & $\begin{array}{c}0,27 \\
(0,06) \\
\end{array}$ & $\begin{array}{c}0,26 \\
(0,06)\end{array}$ \\
\hline $\mathrm{R}^{2}$ ajustado & 24,2 & 22,2 & 22,0 \\
\hline $\mathrm{N}^{\circ}$ de observações & 8.576 & 8.240 & 8.238 \\
\hline $\mathrm{N}^{o}$ de países exportadores & 127 & 120 & 121 \\
\hline \multicolumn{4}{|l|}{324 - Máquinas e equipamentos } \\
\hline $\begin{array}{l}\mathrm{a} 0 \\
\text { (constante) }\end{array}$ & $\begin{array}{l}11,16 \\
(0,06) \\
\end{array}$ & $\begin{array}{l}11,58 \\
(0,03) \\
\end{array}$ & $\begin{array}{l}11,60 \\
(0,03) \\
\end{array}$ \\
\hline $\begin{array}{l}\text { al } \\
\text { Ln(Custo) }\end{array}$ & $\begin{array}{c}-5,05 \\
(0,30) \\
\end{array}$ & $\begin{array}{c}-7,08 \\
(0,15) \\
\end{array}$ & $\begin{array}{c}-6,98 \\
(0,14) \\
\end{array}$ \\
\hline $\begin{array}{l}\mathrm{a} 2 \\
\text { (Dano) }\end{array}$ & $\begin{array}{c}0,34 \\
(0,03) \\
\end{array}$ & $\begin{array}{c}0,32 \\
(0,03) \\
\end{array}$ & $\begin{array}{c}0,31 \\
(0,03) \\
\end{array}$ \\
\hline $\mathrm{R}^{2}$ ajustado & 30,9 & 30,6 & 30,1 \\
\hline $\mathrm{N}^{\circ}$ de observações & 21.338 & 20.781 & 20.631 \\
\hline $\mathrm{N}^{\circ}$ de países exportadores & 141 & 140 & 139 \\
\hline \multicolumn{4}{|l|}{325 - Eletrodomésticos } \\
\hline $\begin{array}{l}\mathrm{a} 0 \\
\text { (constante) }\end{array}$ & $\begin{array}{l}10,07 \\
(0,13) \\
\end{array}$ & $\begin{array}{l}10,27 \\
(0,13)\end{array}$ & $\begin{array}{l}10,24 \\
(0,13)\end{array}$ \\
\hline $\begin{array}{l}\text { al } \\
\text { Ln(Custo) }\end{array}$ & $\begin{array}{c}-4,22 \\
(0,34) \\
\end{array}$ & $\begin{array}{c}-4,68 \\
(0,34) \\
\end{array}$ & $\begin{array}{c}-4,58 \\
(0,34) \\
\end{array}$ \\
\hline
\end{tabular}




\begin{tabular}{|c|c|c|c|}
\hline Código/setor & Modelo 1 & Modelo 2 & Modelo 3 \\
\hline $\begin{array}{l}\text { a2 } \\
\text { (Dano) }\end{array}$ & $\begin{array}{c}0,31 \\
(0,13) \\
\end{array}$ & $\begin{array}{c}0,32 \\
(0,13) \\
\end{array}$ & $\begin{array}{c}0,29 \\
(0,12) \\
\end{array}$ \\
\hline $\mathrm{R}^{2}$ ajustado & 23,0 & 20,3 & 20,4 \\
\hline $\mathrm{N}^{\circ}$ de observações & 1.671 & 1.617 & 1.603 \\
\hline $\mathrm{N}^{\circ}$ de países exportadores & 66 & 65 & 65 \\
\hline \multicolumn{4}{|c|}{326 - Máquinas de escritório e equipamentos de informática } \\
\hline $\begin{array}{l}\mathrm{a} 0 \\
\text { (constante) } \\
\end{array}$ & $\begin{array}{c}10,64 \\
(0,09) \\
\end{array}$ & $\begin{array}{l}10,67 \\
(0,07)\end{array}$ & $\begin{array}{l}10,73 \\
(0,07)\end{array}$ \\
\hline $\begin{array}{l}\text { al } \\
\operatorname{Ln} \text { (Custo) } \\
\end{array}$ & $\begin{array}{c}-5,04 \\
(0,41) \\
\end{array}$ & $\begin{array}{c}-5,31 \\
(0,26) \\
\end{array}$ & $\begin{array}{c}-5,17 \\
(0,26) \\
\end{array}$ \\
\hline $\begin{array}{l}\text { a2 } \\
\text { (Dano) } \\
\end{array}$ & $\begin{array}{c}0,26 \\
(0,08) \\
\end{array}$ & $\begin{array}{c}0,20 \\
(0,08) \\
\end{array}$ & $\begin{array}{c}0,22 \\
(0,08) \\
\end{array}$ \\
\hline $\mathrm{R}^{2}$ ajustado & 22,2 & 20,0 & 20,3 \\
\hline $\mathrm{N}^{\mathrm{o}}$ de observações & 4.740 & 4.587 & 4.583 \\
\hline $\mathrm{N}^{\circ}$ de países exportadores & 119 & 117 & 116 \\
\hline \multicolumn{4}{|c|}{327 - Máquinas, aparelhos e materiais elétricos } \\
\hline $\begin{array}{l}\text { a0 } \\
\text { (constante) } \\
\end{array}$ & $\begin{array}{l}10,67 \\
(0,05) \\
\end{array}$ & $\begin{array}{l}10,98 \\
(0,05) \\
\end{array}$ & $\begin{array}{l}10,96 \\
(0,05) \\
\end{array}$ \\
\hline $\begin{array}{l}\text { al } \\
\operatorname{Ln}(\text { Custo }) \\
\end{array}$ & $\begin{array}{c}-5,34 \\
(0,20) \\
\end{array}$ & $\begin{array}{c}-6,21 \\
(0,17) \\
\end{array}$ & $\begin{array}{c}-6,16 \\
(0,17) \\
\end{array}$ \\
\hline $\begin{array}{l}\text { a2 } \\
\text { (Dano) } \\
\end{array}$ & $\begin{array}{c}0,24 \\
(0,05) \\
\end{array}$ & $\begin{array}{c}0,18 \\
(0,05) \\
\end{array}$ & $\begin{array}{c}0,18 \\
(0,05) \\
\end{array}$ \\
\hline $\mathrm{R}^{2}$ ajustado & 30,9 & 28,7 & 28,2 \\
\hline $\mathrm{N}^{\circ}$ de observações & 11.225 & 10.872 & 10.819 \\
\hline $\mathrm{N}^{\circ}$ de países exportadores & 133 & 132 & 132 \\
\hline \multicolumn{4}{|c|}{328 - Material eletrônico e equipamentos de comunicações } \\
\hline $\begin{array}{l}\mathrm{a} 0 \\
\text { (constante) }\end{array}$ & $\begin{array}{l}10,36 \\
(0,06) \\
\end{array}$ & $\begin{array}{l}10,58 \\
(0,05) \\
\end{array}$ & $\begin{array}{l}10,67 \\
(0,05) \\
\end{array}$ \\
\hline $\begin{array}{l}\text { al } \\
\text { Ln(Custo) }\end{array}$ & $\begin{array}{c}-4,33 \\
(0,35) \\
\end{array}$ & $\begin{array}{c}5,39 \\
(0,19) \\
\end{array}$ & $\begin{array}{c}5,65 \\
(0,19) \\
\end{array}$ \\
\hline $\begin{array}{l}\text { a2 } \\
\text { (Dano) } \\
\end{array}$ & $\begin{array}{c}0,17 \\
(0,05) \\
\end{array}$ & $\begin{array}{c}0,08 \\
(0,05) \\
\end{array}$ & $\begin{array}{c}0,09 \\
(0,05) \\
\end{array}$ \\
\hline $\mathrm{R}^{2}$ ajustado & 28,5 & 26,4 & 26,2 \\
\hline $\mathrm{N}^{\circ}$ de observações & 10.538 & 9.940 & 10.075 \\
\hline $\mathrm{N}^{\circ}$ de países exportadores & 142 & 135 & 136 \\
\hline \multicolumn{4}{|c|}{329 - Aparelhos e instrumentos médico e ótico } \\
\hline $\begin{array}{l}\mathrm{a} 0 \\
\text { (constante) }\end{array}$ & $\begin{array}{l}10,68 \\
(0,10) \\
\end{array}$ & $\begin{array}{l}10,94 \\
(0,05) \\
\end{array}$ & $\begin{array}{l}10,90 \\
(0,05) \\
\end{array}$ \\
\hline $\begin{array}{l}\text { al } \\
\operatorname{Ln}(\text { Custo }) \\
\end{array}$ & $\begin{array}{c}-6,21 \\
(0,55) \\
\end{array}$ & $\begin{array}{c}-7,14 \\
(0,20) \\
\end{array}$ & $\begin{array}{c}-6,89 \\
(0,20) \\
\end{array}$ \\
\hline $\begin{array}{l}\text { a2 } \\
\text { (Dano) } \\
\end{array}$ & $\begin{array}{c}0,30 \\
(0,05) \\
\end{array}$ & $\begin{array}{c}0,26 \\
(0,05) \\
\end{array}$ & $\begin{array}{c}0,25 \\
(0,05) \\
\end{array}$ \\
\hline $\mathrm{R}^{2}$ ajustado & 26,2 & 26,0 & 24,7 \\
\hline $\mathrm{N}^{\circ}$ de observações & 10.550 & 10.256 & 10,144 \\
\hline $\mathrm{N}^{\circ}$ de países exportadores & 111 & 111 & 110 \\
\hline \multicolumn{4}{|c|}{330 - Automóveis, camionetas e utilitários } \\
\hline $\begin{array}{l}\mathrm{a} 0 \\
\text { (constante) }\end{array}$ & $\begin{array}{l}13,85 \\
(0,43) \\
\end{array}$ & $\begin{array}{l}12,73 \\
(0,45) \\
\end{array}$ & $\begin{array}{l}13,73 \\
(0,45) \\
\end{array}$ \\
\hline $\begin{array}{l}\text { al } \\
\text { Ln(Custo) }\end{array}$ & $\begin{array}{c}-7,29 \\
(1,20) \\
\end{array}$ & $\begin{array}{c}-5,31 \\
(1,26) \\
\end{array}$ & $\begin{array}{c}-6,23 \\
(1,36) \\
\end{array}$ \\
\hline $\begin{array}{l}\text { a2 } \\
\text { (Dano) } \\
\end{array}$ & $\begin{array}{c}0,39 \\
(0,41) \\
\end{array}$ & $\begin{array}{c}0,34 \\
(0,41) \\
\end{array}$ & $\begin{array}{c}0,30 \\
(0,41) \\
\end{array}$ \\
\hline $\mathrm{R}^{2}$ ajustado & 14,8 & 5,4 & 11,5 \\
\hline $\mathrm{N}^{\circ}$ de observações & 284 & 241 & 276 \\
\hline
\end{tabular}




\begin{tabular}{|c|c|c|c|}
\hline Código/setor & Modelo 1 & Modelo 2 & Modelo 3 \\
\hline $\mathrm{N}^{\circ}$ de países exportadores & 37 & 37 & 37 \\
\hline \multicolumn{4}{|l|}{331 - Caminhões e ônibus } \\
\hline $\begin{array}{l}\mathrm{a} 0 \\
\text { (constante) } \\
\end{array}$ & $\begin{array}{l}14,01 \\
(0,77) \\
\end{array}$ & $\begin{array}{l}12,57 \\
(0,62) \\
\end{array}$ & $\begin{array}{l}13,71 \\
(0,71) \\
\end{array}$ \\
\hline $\begin{array}{l}\text { al } \\
\text { Ln(Custo) }\end{array}$ & $\begin{array}{c}-6,40 \\
(2,40) \\
\end{array}$ & $\begin{array}{c}-2,32 \\
(1,76) \\
\end{array}$ & $\begin{array}{c}-5,00 \\
(1,98) \\
\end{array}$ \\
\hline $\begin{array}{l}\text { a2 } \\
\text { (Dano) }\end{array}$ & $\begin{array}{c}-0,08 \\
(0,66) \\
\end{array}$ & $\begin{array}{c}-0,27 \\
(0,55) \\
\end{array}$ & $\begin{array}{c}0,01 \\
(0,61) \\
\end{array}$ \\
\hline $\mathrm{R}^{2}$ ajustado & 22,4 & 22,7 & 29,3 \\
\hline $\mathrm{N}^{\circ}$ de observações & 91 & 80 & 89 \\
\hline $\mathrm{N}^{\circ}$ de países exportadores & 22 & 22 & 22 \\
\hline \multicolumn{4}{|c|}{332 - Peças e acessórios para veículos } \\
\hline $\begin{array}{l}\mathrm{a} 0 \\
\text { (constante) }\end{array}$ & $\begin{array}{l}11,17 \\
(0,10) \\
\end{array}$ & $\begin{array}{l}11,37 \\
(0,09) \\
\end{array}$ & $\begin{array}{l}11,49 \\
(0,09) \\
\end{array}$ \\
\hline $\begin{array}{l}\text { al } \\
\operatorname{Ln} \text { (Custo) } \\
\end{array}$ & $\begin{array}{c}-4,83 \\
(0,33) \\
\end{array}$ & $\begin{array}{c}5,78 \\
(0,28) \\
\end{array}$ & $\begin{array}{c}5,88 \\
(0,29) \\
\end{array}$ \\
\hline $\begin{array}{l}\text { a2 } \\
\text { (Dano) }\end{array}$ & $\begin{array}{c}0,39 \\
(0,09) \\
\end{array}$ & $\begin{array}{c}0,31 \\
(0,09)\end{array}$ & $\begin{array}{c}0,31 \\
(0,09) \\
\end{array}$ \\
\hline $\mathrm{R}^{2}$ ajustado & 40,7 & 38,5 & 39,2 \\
\hline $\mathrm{N}^{\circ}$ de observações & 3.479 & 3.320 & 3.363 \\
\hline $\mathrm{N}^{\circ}$ de países exportadores & 104 & 100 & 99 \\
\hline \multicolumn{4}{|c|}{333 - Outros equipamentos de transporte } \\
\hline $\begin{array}{l}\mathrm{a} 0 \\
\text { (constante) } \\
\end{array}$ & $\begin{array}{l}11,08 \\
(0,23) \\
\end{array}$ & $\begin{array}{l}11,45 \\
(0,15) \\
\end{array}$ & $\begin{array}{l}11,70 \\
(0,15) \\
\end{array}$ \\
\hline $\begin{array}{l}\text { al } \\
\text { Ln(Custo) }\end{array}$ & $\begin{array}{c}-4,53 \\
(1,15) \\
\end{array}$ & $\begin{array}{c}-7,35 \\
(0,49) \\
\end{array}$ & $\begin{array}{c}-7,90 \\
(0,52) \\
\end{array}$ \\
\hline $\begin{array}{l}\mathrm{a} 2 \\
\text { (Dano) }\end{array}$ & $\begin{array}{c}0,52 \\
(0,16) \\
\end{array}$ & $\begin{array}{c}0,38 \\
(0,15) \\
\end{array}$ & $\begin{array}{c}0,45 \\
(0,15) \\
\end{array}$ \\
\hline $\mathrm{R}^{2}$ ajustado & 25,3 & 26,8 & 27,3 \\
\hline $\mathrm{N}^{o}$ de observações & 1.186 & 1.098 & 1.110 \\
\hline $\mathrm{N}^{\circ}$ de países exportadores & 61 & 58 & 58 \\
\hline \multicolumn{4}{|l|}{334 - Móveis e produtos diversos } \\
\hline $\begin{array}{l}\mathrm{a} 0 \\
\text { (constante) }\end{array}$ & $\begin{array}{c}9,15 \\
(0,08) \\
\end{array}$ & $\begin{array}{c}9,75 \\
(0,08) \\
\end{array}$ & $\begin{array}{c}9,70 \\
(0,08) \\
\end{array}$ \\
\hline $\begin{array}{l}\text { al } \\
\text { Ln(Custo) }\end{array}$ & $\begin{array}{c}-2,19 \\
(0,19) \\
\end{array}$ & $\begin{array}{c}-3,74 \\
(0,18) \\
\end{array}$ & $\begin{array}{c}-3,67 \\
(0,18) \\
\end{array}$ \\
\hline $\begin{array}{l}\mathrm{a} 2 \\
\text { (Dano) }\end{array}$ & $\begin{array}{c}0,32 \\
(0,07) \\
\end{array}$ & $\begin{array}{c}0,29 \\
(0,07) \\
\end{array}$ & $\begin{array}{c}0,25 \\
(0,07) \\
\end{array}$ \\
\hline $\mathrm{R}^{2}$ ajustado & 24,9 & 22,2 & 20,7 \\
\hline $\mathrm{N}^{\circ}$ de observações & 5.124 & 4.952 & 4.903 \\
\hline $\mathrm{N}^{\circ}$ de países exportadores & 100 & 99 & 99 \\
\hline
\end{tabular}




\section{Apêndice B - Resultados por setor GTAP}

Equação estimada:

$$
\operatorname{LnVM} M_{i r}=a_{0}+a_{i r}+a_{1} \text { LnCusto }+a_{2} D_{a n o}+e_{i r}
$$

Onde:

$$
\text { Custo }=1+C T_{i r}+T_{i r}+C T_{i r}{ }^{\star} T_{i r}
$$

Método de estimação: mínimos quadrados ordinários.

\begin{tabular}{|c|c|c|c|c|c|c|}
\hline Setor & $\begin{array}{c}\mathrm{a}_{0} \\
\text { (constante) }\end{array}$ & $\begin{array}{c}a_{1} \\
\text { LnCusto }\end{array}$ & $\begin{array}{c}a_{2} \\
\text { Dano }\end{array}$ & $\begin{array}{c}\mathbf{R}^{2} \\
\text { ajustado }\end{array}$ & $\begin{array}{l}\text { No de } \\
\text { países } \\
\text { export. }\end{array}$ & $\begin{array}{c}\text { No de } \\
\text { obs. }\end{array}$ \\
\hline Arroz & $\begin{array}{l}14,60 \\
(1,18) \\
\end{array}$ & $\begin{array}{r}-10,25 \\
(5,23) \\
\end{array}$ & $\begin{array}{c}-1,86 \\
(1,13) \\
\end{array}$ & 37,2 & 9 & 29 \\
\hline Trigo & $\begin{array}{c}7,33 \\
(6,62) \\
\end{array}$ & $\begin{array}{c}57,16 \\
(48,19) \\
\end{array}$ & $\begin{array}{c}-2,49 \\
(2,66) \\
\end{array}$ & $-16,4$ & 9 & 19 \\
\hline Cereais em grãos não especificados & $\begin{array}{l}11,78 \\
(0,64) \\
\end{array}$ & $\begin{array}{c}-3,89 \\
(2,31) \\
\end{array}$ & $\begin{array}{c}0,67 \\
(0,87) \\
\end{array}$ & 6,0 & 25 & 69 \\
\hline Vegetais, frutas e nozes & $\begin{array}{l}11,65 \\
(0,22) \\
\end{array}$ & $\begin{array}{c}-4,36 \\
(0,73) \\
\end{array}$ & $\begin{array}{c}0,42 \\
(0,23) \\
\end{array}$ & 22,8 & 49 & 476 \\
\hline Sementes oleaginosas & $\begin{array}{l}11,33 \\
(0,50) \\
\end{array}$ & $\begin{array}{c}4,48 \\
(1,25) \\
\end{array}$ & $\begin{array}{c}0,18 \\
(0,58) \\
\end{array}$ & 35,3 & 24 & 73 \\
\hline Fibras de plantas & $\begin{array}{l}14,98 \\
(0,73) \\
\end{array}$ & $\begin{array}{r}-12,73 \\
(5,12) \\
\end{array}$ & $\begin{array}{c}0,76 \\
(0,75) \\
\end{array}$ & 42,2 & 32 & 58 \\
\hline Outras culturas não especificadas & $\begin{array}{l}10,70 \\
(0,18) \\
\end{array}$ & $\begin{array}{c}-5,75 \\
(0,62) \\
\end{array}$ & $\begin{array}{c}0,18 \\
(0,19) \\
\end{array}$ & 28,1 & 79 & 665 \\
\hline Bovinos, ovinos, caprinos e cavalos & $\begin{array}{l}1,21 \\
(0,31) \\
\end{array}$ & $\begin{array}{c}-3,55 \\
(0,70) \\
\end{array}$ & $\begin{array}{c}0,35 \\
(0,36) \\
\end{array}$ & 37,8 & 23 & 73 \\
\hline Animais não especificados & $\begin{array}{l}12,39 \\
(0,22) \\
\end{array}$ & $\begin{array}{c}-8,58 \\
(1,23) \\
\end{array}$ & $\begin{array}{c}-0,26 \\
(0,28) \\
\end{array}$ & 20,7 & 29 & 216 \\
\hline Lã e seda & $\begin{array}{l}11,64 \\
(0,48) \\
\end{array}$ & $\begin{array}{r}-12,49 \\
(2,11) \\
\end{array}$ & $\begin{array}{c}0,89 \\
(0,44) \\
\end{array}$ & 95,8 & 7 & 12 \\
\hline Silvicultura & $\begin{array}{c}9,78 \\
(0,29) \\
\end{array}$ & $\begin{array}{c}4,14 \\
(1,00) \\
\end{array}$ & $\begin{array}{c}0,48 \\
(0,33) \\
\end{array}$ & 35,9 & 52 & 171 \\
\hline Pesca & $\begin{array}{l}10,74 \\
(0,33) \\
\end{array}$ & $\begin{array}{c}-4,57 \\
(0,74) \\
\end{array}$ & $\begin{array}{c}-0,14 \\
(0,38) \\
\end{array}$ & 34,9 & 30 & 127 \\
\hline Setor & $\begin{array}{c}\mathrm{a}_{0} \\
\text { (constante) }\end{array}$ & $\stackrel{a_{1}}{\text { LnCusto }}$ & $\begin{array}{c}a_{2} \\
\text { Dano }\end{array}$ & $\begin{array}{c}\mathbf{R}^{2} \\
\text { ajustado }\end{array}$ & $\begin{array}{l}\text { No de } \\
\text { países } \\
\text { export. }\end{array}$ & $\begin{array}{c}\text { No de } \\
\text { obs. }\end{array}$ \\
\hline Carvão & $\begin{array}{l}13,66 \\
(0,90) \\
\end{array}$ & $\begin{array}{c}2,34 \\
(3,94) \\
\end{array}$ & $\begin{array}{c}1,08 \\
(0,66) \\
\end{array}$ & 38,7 & 28 & 73 \\
\hline Petróleo & $\begin{array}{l}14,81 \\
(3,34)\end{array}$ & $\begin{array}{c}68,22 \\
(73,57)\end{array}$ & $\begin{array}{c}0,83 \\
(0,89)\end{array}$ & 90,3 & 24 & 30 \\
\hline Gás natural & \multicolumn{6}{|c|}{ Número insuficiente de observações } \\
\hline
\end{tabular}

Os valores entre parênteses correspondem ao erro padrão robusto. 


\begin{tabular}{|c|c|c|c|c|c|c|}
\hline Minerais não especificados & $\begin{array}{l}10,41 \\
(0,17) \\
\end{array}$ & $\begin{array}{c}-3,16 \\
(0,42) \\
\end{array}$ & $\begin{array}{c}0,31 \\
(0,17) \\
\end{array}$ & 17,1 & 80 & 1.028 \\
\hline Carne bovina & $\begin{array}{l}12,96 \\
(0,59)\end{array}$ & $\begin{array}{r}-11,84 \\
(4,97)\end{array}$ & $\begin{array}{c}0,47 \\
(0,59)\end{array}$ & 40,3 & 10 & 65 \\
\hline Outras carnes não especificadas & $\begin{array}{l}10,88 \\
(0,25) \\
\end{array}$ & $\begin{array}{c}-5,09 \\
(0,81) \\
\end{array}$ & $\begin{array}{c}0,61 \\
(0,32) \\
\end{array}$ & 18,2 & 24 & 142 \\
\hline Óleos e gorduras vegetais & $\begin{array}{l}11,37 \\
(0,24)\end{array}$ & $\begin{array}{c}-5,78 \\
(0,68)\end{array}$ & $\begin{array}{c}0,00 \\
(0,25)\end{array}$ & 33,3 & 52 & 443 \\
\hline Laticínios & $\begin{array}{l}11,89 \\
(0,29)\end{array}$ & $\begin{array}{c}-3,85 \\
(0,85) \\
\end{array}$ & $\begin{array}{c}0,49 \\
(0,27) \\
\end{array}$ & 35,5 & 28 & 266 \\
\hline Arroz beneficiado & $\begin{array}{l}1,16 \\
(1,53) \\
\end{array}$ & $\begin{array}{c}3,15 \\
(6,00) \\
\end{array}$ & $\begin{array}{c}-0,30 \\
(0,82) \\
\end{array}$ & 25,5 & 17 & 56 \\
\hline Açúcar & $\begin{array}{c}6,33 \\
(0,81) \\
\end{array}$ & $\begin{array}{c}0,09 \\
(2,25) \\
\end{array}$ & $\begin{array}{c}0,69 \\
(0,77) \\
\end{array}$ & 25,7 & 23 & 48 \\
\hline Outros produtos alimentares & $\begin{array}{l}10,72 \\
(0,08) \\
\end{array}$ & $\begin{array}{r}-4,80 \\
(0,27) \\
\end{array}$ & $\begin{array}{c}0,15 \\
(0,08) \\
\end{array}$ & 24,3 & 90 & 3.486 \\
\hline Bebidas e fumo & $\begin{array}{l}11,18 \\
(0,24) \\
\end{array}$ & $\begin{array}{c}-4,44 \\
(0,57) \\
\end{array}$ & $\begin{array}{c}0,29 \\
(0,25) \\
\end{array}$ & 12,3 & 51 & 445 \\
\hline Têxteis & $\begin{array}{l}10,69 \\
(0,06)\end{array}$ & $\begin{array}{c}-6,30 \\
(0,17) \\
\end{array}$ & $\begin{array}{c}0,43 \\
(0,05) \\
\end{array}$ & 20,3 & 110 & 8.574 \\
\hline Vestuário & $\begin{array}{c}8,97 \\
(0,07) \\
\end{array}$ & $\begin{array}{r}-4,59 \\
(0,23) \\
\end{array}$ & $\begin{array}{c}0,43 \\
(0,06) \\
\end{array}$ & 24,2 & 108 & 5.820 \\
\hline Produtos de couro & $\begin{array}{l}10,38 \\
(0,10) \\
\end{array}$ & $\begin{array}{c}-5,00 \\
(0,31) \\
\end{array}$ & $\begin{array}{c}0,22 \\
(0,10) \\
\end{array}$ & 33,2 & 96 & 2.041 \\
\hline Produtos de madeia & $\begin{array}{c}9,28 \\
(0,13) \\
\end{array}$ & $\begin{array}{c}-3,29 \\
(0,31) \\
\end{array}$ & $\begin{array}{c}0,40 \\
(0,12) \\
\end{array}$ & 20,7 & 80 & 1.464 \\
\hline Setor & $\begin{array}{c}\mathrm{a}_{0} \\
\text { (constante) }\end{array}$ & $\begin{array}{c}a_{1} \\
\text { LnCusto }\end{array}$ & $\begin{array}{c}a_{2} \\
\text { Dano }\end{array}$ & $\begin{array}{c}\mathbf{R}^{2} \\
\text { ajustado }\end{array}$ & $\begin{array}{l}\mathrm{N}^{\circ} \mathrm{de} \\
\text { países } \\
\text { export. }\end{array}$ & $\begin{array}{c}\text { No de } \\
\text { obs. }\end{array}$ \\
\hline Papel e gráfica & $\begin{array}{l}10,31 \\
(0,09)\end{array}$ & $\begin{array}{c}-5,03 \\
(0,23)\end{array}$ & $\begin{array}{c}0,28 \\
(0,09)\end{array}$ & 23,8 & 91 & 3.689 \\
\hline Refino de petróleo e carvão & $\begin{array}{l}12,30 \\
(0,23) \\
\end{array}$ & $\begin{array}{c}-6,27 \\
(0,72) \\
\end{array}$ & $\begin{array}{c}0,42 \\
(0,25) \\
\end{array}$ & 34,3 & 67 & 655 \\
\hline Química, borracha e produtos plásticos & $\begin{array}{l}11,05 \\
(0,02) \\
\end{array}$ & $\begin{array}{c}-5,71 \\
(0,08) \\
\end{array}$ & $\begin{array}{c}0,12 \\
(0,03) \\
\end{array}$ & 14,9 & 150 & 40.872 \\
\hline Produtos minerais & $\begin{array}{l}10,25 \\
(0,07) \\
\end{array}$ & $\begin{array}{c}-4,54 \\
(0,19) \\
\end{array}$ & $\begin{array}{c}0,36 \\
(0,07) \\
\end{array}$ & 20,5 & 91 & 5.094 \\
\hline Metais ferrosos & $\begin{array}{l}11,14 \\
(0,07) \\
\end{array}$ & $\begin{array}{c}-5,46 \\
(0,24) \\
\end{array}$ & $\begin{array}{c}0,49 \\
(0,07) \\
\end{array}$ & 20,9 & 90 & 4.604 \\
\hline Metais não especificados & $\begin{array}{l}11,12 \\
(0,09) \\
\end{array}$ & $\begin{array}{c}-7,57 \\
(0,34) \\
\end{array}$ & $\begin{array}{c}0,25 \\
(0,09) \\
\end{array}$ & 22,1 & 95 & 3.174 \\
\hline Produtos de metais & $\begin{array}{l}10,12 \\
(0,06) \\
\end{array}$ & $\begin{array}{c}-5,25 \\
(0,17) \\
\end{array}$ & $\begin{array}{c}0,26 \\
(0,05) \\
\end{array}$ & 22,6 & 126 & 9.093 \\
\hline Veículos automotores, partes e peças & $\begin{array}{l}11,93 \\
(0,09) \\
\end{array}$ & $\begin{array}{r}-6,28 \\
(0,29) \\
\end{array}$ & $\begin{array}{c}0,32 \\
(0,09) \\
\end{array}$ & 32,5 & 87 & 3.287 \\
\hline Equipamentos de transporte não especif. & $\begin{array}{l}11,75 \\
(0,16) \\
\end{array}$ & $\begin{array}{c}-7,76 \\
(0,51) \\
\end{array}$ & $\begin{array}{c}0,46 \\
(0,15) \\
\end{array}$ & 26,4 & 58 & 1.054 \\
\hline Equipamento eletrônico & $\begin{array}{l}10,70 \\
(0,04) \\
\end{array}$ & $\begin{array}{c}-5,56 \\
(0,15) \\
\end{array}$ & $\begin{array}{c}0,13 \\
(0,04) \\
\end{array}$ & 24,3 & 158 & 14.192 \\
\hline Máquinas e equipamento não especificados & $\begin{array}{l}11,20 \\
(0,02) \\
\end{array}$ & $\begin{array}{c}-6,62 \\
(0,09) \\
\end{array}$ & $\begin{array}{c}0,26 \\
(0,02)\end{array}$ & 26,4 & 166 & 44.325 \\
\hline Outros manufaturados não especificados & $\begin{array}{c}9,82 \\
(0,08)\end{array}$ & $\begin{array}{c}-3,86 \\
(0,20)\end{array}$ & $\begin{array}{c}0,28 \\
(0,07)\end{array}$ & 20,0 & 99 & 4.442 \\
\hline
\end{tabular}

